\title{
Regulation of Gastric Electrical and Mechanical Activity by Cholinesterases in Mice
}

\author{
Amy A Worth, ${ }^{1}$ Abigail S Forrest, ${ }^{2}$ Lauren E Peri, ${ }^{3}$ Sean M Ward, ${ }^{3}$ Grant W Hennig ${ }^{3}$ and Kenton M Sanders ${ }^{3 *}$ \\ ${ }^{1}$ Faculty of Life Sciences, University of Manchester, Manchester, United Kingdom; ' ${ }^{2}$ Charles Rivers Laboratory, Reno, Nevada, USA; \\ and ${ }^{3}$ Department of Physiology and Cell Biology, University of Nevada School of Medicine, Reno, Nevada, USA
}

\section{Background/Aims}

Gastric peristalsis begins in the orad corpus and propagates to the pylorus. Directionality of peristalsis depends upon orderly generation and propagation of electrical slow waves and a frequency gradient between proximal and distal pacemakers. We sought to understand how chronotropic agonists affect coupling between corpus and antrum.

\section{Methods}

Electrophysiological and imaging techniques were used to investigate regulation of gastric slow wave frequency by muscarinic agonists in mice. We also investigated the expression and role of cholinesterases in regulating slow wave frequency and motor patterns in the stomach.

\section{Results}

Both acetycholinesterase (Ache) and butyrylcholine esterase (Bche) are expressed in gastric muscles and AChE is localized to varicose processes of motor neurons. Inhibition of AChE in the absence of stimulation increased slow wave frequency in corpus and throughout muscle strips containing corpus and antrum. CCh caused depolarization and increased slow wave frequency. Stimulation of cholinergic neurons increased slow wave frequency but did not cause depolarization. Neostigmine $(1 \mu \mathrm{M})$ increased slow wave frequency, but uncoupling between corpus and antrum was not detected. Motility mapping of contractile activity in gastric muscles showed similar effects of enteric nerve stimulation on the frequency and propagation of slow waves, but neostigmine $(>1 \mu \mathrm{M})$ caused aberrant contractile frequency and propagation and ectopic pacemaking.

\section{Conclusions}

Our data show that slow wave uncoupling is difficult to assess with electrical recording from a single or double sites and suggest that efficient metabolism of ACh released from motor neurons is an extremely important regulator of slow wave frequency and propagation and gastric motility patterns.

\section{(J Neurogastroenterol Motil 2015;21:200-216)}

\section{Key Words}

Cholinesterase; Peristalsis; Slow wave; Smooth muscle; Stomach

Received: October 14, 2014 Revised: November 15, 2014 Accepted: November 18, 2014

(c) This is an Open Access article distributed under the terms of the Creative Commons Attribution Non-Commercial License (http://creativecommons org/licenses/by-nc/3.0) which permits unrestricted non-commercial use, distribution, and reproduction in any medium, provided the original work is properly cited.

*Correspondence: Kenton M Sanders, PhD

Department of Physiology and Cell Biology, University of Nevada School of Medicine, Reno, Nevada 89557, USA

Tel: +1-775-784-6908, Fax: +1-775-784-6903, E-mail: ksanders@medicine.nevada.edu

Amy A Worth and Abigail S Forrest contributed equally to this study.

Financial support: This project was funded by R37 DK40569 and a COBRE award (P20 RR018751).

Conflicts of interest: None.

Author contributions: Amy A Worth performed imaging studies on gastric muscle sheets and analyzed data, and contributed to the writing of the initial draft of the paper; Abigail S Forrest performed electrophysiological, Western blots and immunohistochemistry experiments, and contributed to the writing of the first draft of the paper; Lauren E Peri planned and oversaw molecular studies; Sean M Ward analyzed planned and oversaw immunohistochemistry experiments, and edited drafts of the paper; Grant W Hennig planned imaging experiments, analyzed all imaging data, and wrote and edited the paper; and Kenton M Sanders conceived of the study, planned electrophysiological experiments, and wrote and edited the paper. 


\section{Introduction}

Electrical slow waves underlie the sweeping peristaltic contractions in the vertebrate stomach that are important for efficient reduction in food particle size and gastric empting. ${ }^{1}$ Gastric slow waves are initiated by interstitial cells of Cajal. ${ }^{2,3}$ The proximalto-distal directionality of gastric peristaltic waves is determined by a pacemaker frequency gradient in which intrinsic higher frequency characteristics of the myenteric interstitial cells of Cajal (ICC-MY) network in the proximal stomach entrain the intrinsically slower frequencies of the distal stomach. ${ }^{4}$ For example, in longitudinal strips of murine stomach, slow waves are generated at about 8 cycles per minute (cpm) in the orad corpus and these events are recorded in the antrum at this frequency. ${ }^{5}$ When the antrum is separated physically from the corpus, the intrinsic antral frequency falls to only 2-4 cpm. Studies on ICC isolated from the corpus and antrum suggest that the frequency gradient is coded intrinsically in the ICC from these regions. ${ }^{6}$ Previous studies have also demonstrated that pacemaker activity is intrinsic to ICC and is not generated by neural inputs, because neurotoxins, such as tetrodotoxin (TTX), do not inhibit slow waves.

There are at least 2 distinct classes of ICC in the stomach. ICC-MY lie in the plane of the myenteric plexus between the circular and longitudinal muscle layers, ${ }^{7,8}$ and intramuscular ICC (ICC-IM) lie within muscle bundles throughout most of the stomach. ${ }^{9}$ However, examination of antral longitudinal muscles of some species shows few ICC-IM in this region. ${ }^{10}$ While ICCMY are generally thought to serve as the dominant pacemakers in the stomach, ${ }^{11}$ some studies have suggested that the dominant frequency in the orad corpus (and therefore the dominant frequency of the stomach) is generated by ICC-IM. ${ }^{12}$ Slow wave frequency is modulated by antral distension ${ }^{13}$ or through inputs from enteric neurons, ${ }^{5,14}$ and this regulation is mediated via ICCIM because it is diminished or missing in Kit mutant animals lacking this class of ICC.

As described above, the proximal-to-distal slow wave frequency gradient is essential for normal gastric peristalsis, and it is thought that disruption of this gradient by emergence of rapid or arrhythmic electrical activity in the antrum may be a cause of gastric emptying disorders and symptoms of functional GI disorders. ${ }^{15,16}$ Loss of continuity in the ICC network, as occurs in diabetes, may also contribute to the inability of slow waves to propagate normally from corpus to pylorus and may predispose antral ICC network to display ectopic pacemaker activity. ${ }^{17} \mathrm{In}$ - flammatory processes, including the generation of prostaglandins may also exert chronotropic effects and raise antral pacemaker frequency, breaking down the normal frequency gradient. ${ }^{18}$

Acetylcholine (ACh), the dominant excitatory neurotransmitter in the GI tract, is released from enteric excitatory motor neurons. ${ }^{1}$ $\mathrm{ACh}$ has ionotropic and chronotropic effects on gastric muscles, ${ }^{19,20}$ and may increase slow wave amplitude and frequency and the fidelity of propagation in the post-prandial state. After release from neurons, $\mathrm{ACh}$ is efficiently metabolized by cholinesterases (AChE and $\mathrm{BChE}$ ). AChE, the dominant esterase in gastric muscles, is a tetrameric protein that hydrolyses ACh into choline and acetic acid. Choline can be recovered by a pre-synaptic high affinity choline transporter expressed by cholinergic neurons and reprocessed to synthesize new ACh. ${ }^{21}$ We previously reported a significant increase in antral slow wave frequency when muscles were exposed to inhibitors of cholinesterases, and this effect was blocked by TTX or atropine. ${ }^{5}$ Thus, tonic activity of cholinergic neurons appears to release $\mathrm{ACh}$ on an ongoing basis, but efficient metabolism of ACh constrains the chronotropic drive of ACh on antral pacemakers. This role of cholinesterases, particularly in the antrum, may contribute significantly to maintenance of the proximal-to-distal slow wave frequency gradient. In the present study we have characterized the expression of cholinesterases and distribution of $\mathrm{AChE}$ in murine gastric muscles and characterized regulation of slow wave frequency and gastric motility by $\mathrm{ACh}$ metabolism. Disruption of this pathway can lead to enhanced electrical slow wave frequency, depolarization and disorganized gastric motility. The study suggests the hypothesis that loss or defects in cholinesterase expression or distribution could contribute to the development of gastric dysrhythmias and abnormalities in organization and propagation of gastric peristalsis.

\section{Materials and Methods}

\section{Animals}

$\mathrm{BALB} / \mathrm{c}$ mice (Charles River Laboratories, Wilmington, MA, USA), WBB6F1/J-Kit ${ }^{W} / \mathrm{Kit}^{{ }^{W v}}\left(W / W^{v}\right)$ mice and WBB6F1/J-Kit ${ }^{+} /$ $\mathrm{Kit}^{+}$wild-type controls (Jackson Laboratories, Bar Harbor, ME, USA) of either sex were anaesthetized using isoflurane inhalation and killed by cervical dislocation. The stomachs were removed and opened along the lesser curvature. The luminal contents were washed away using Krebs-Ringer bicarbonate solution (KRB) and the mucosa was removed by sharp dissection. The use of animals was approved for these experiments by the Institutional 
Care and Use Committee (IACUC) at the University of Nevada.

\section{Analysis of Cholinesterase Gene Expression}

Total RNA was isolated from mouse brain and gastric tunica muscularis using TRIzol reagent (Invitrogen, Carlsbad, CA, USA) and the RNA was treated with $1 \mathrm{U} / \mu \mathrm{L}$ DNase I (Promega Corp., Madison, WI, USA). First-strand cDNA was prepared from RNA using oligo $\mathrm{dT}_{(12-18)}$ primer and SuperScript $\mathrm{II}^{\mathrm{TM}}$ reverse transcriptase (Invitrogen). PCR was performed using AmpliTaq Gold ${ }^{\circledR}$ PCR mix (Applied Biosystems, Foster City, CA, USA) and specific primers: AChE (NM_009599; sense GACTTCCTCAGTGACACACCGGA, antisense GAGATTCATTGTCTTTGCTGAAGCCTG), butyrylcholinesterase (BChE) (NM_ 009738; sense ACCCAGGGCAATAGCACAATGTGGC, antisense CTGCCTTCCACTCTTGCTCCGTTTCA); glyceraldehyde-3-phosphate dehydrogenase (GAPDH; NM_008084; sense GTCTTCACCACCATGGAGA, antisense AAGCAGTTGGTGGTGCAG. No-template PCR reactions served as controls for primer contamination. PCR reactions were performed in a GeneAmp 2720 thermal cycler (Applied Biosystems) with an amplification profile of $95^{\circ} \mathrm{C}$ for 10 minutes, then 35 cycles at $95^{\circ} \mathrm{C}$ for 15 seconds, $60^{\circ} \mathrm{C}$ for 20 seconds, and $72^{\circ} \mathrm{C}$ for 30 seconds. PCR amplified fragments were sequenced to confirm the specificity of the primers. Real-time quantitative PCR was performed on an ABI Prism 7000 sequence detector (Applied Biosystems) using SYBR Green chemistry with gene-specific primers. GAPDH was used as a reference gene. Standard curves were generated for each set of primers using serially diluted solutions of cDNA. The slope of the standard curves for AChE, $\mathrm{BChE}$, and GAPDH were similar, thus, the efficiency of the primer sets were considered equal and permitted relative quantitation of transcripts. Unknown quantities for AChE and $\mathrm{BChE}$ relative to the standard curve were calculated and these values were normalized to endogenous GAPDH RNA within the same cDNA sample. cDNA was prepared from 3 mice and each cDNA was tested in triplicate. Data are presented as standard error of the mean (SEM).

\section{Western Blotting}

Frozen peeled BALB/c antral and corpus tunica muscularis were homogenized in lysis buffer (composition: Tris-HCl, 20 $\mathrm{mM}$; Sucrose, 10\%; ethylenediaminetetraacetic acid [EDTA], 1 mM; Triton-X-100, $0.1 \mathrm{mM}$; phenylmethanesulphonylfluoride [PMSF], $0.1 \mathrm{mM}$; Pepstatin A, $1.5 \mathrm{nM}$ using a glass grinder). The homogenate was centrifuged at $16000 \mathrm{rpm}$ for 15 minutes at $4^{\circ} \mathrm{C}$. The supernatant was removed from the pellet and transferred into clean tubes. Protein concentrations of the supernatant were determined using a Bradford assay using bovine gamma globulin as standard. The proteins were separated by SDS- PAGE (10\% gel) and transferred to nitrocellulose by Western blotting. The blots were incubated with primary (AChE E-19 goat polyclonal IgG; Santa Cruz Biotechnology, Santa Cruz, CA, USA) and secondary (rabbit anti-goat; Santa Cruz Biotechnology, Santa Cruz) antibodies. The membrane was washed and processed for enhanced chemiluminescence image detection using ECL advantage (Amersham Biosciences, Piscataway, NJ, USA). Protein bands were visualized with a CCD-camera based detection system (Epi Chem II, UVP Laboratory Products). The collected Tiff images were analyzed using Adobe Photoshop. The specificity of the bands was tested using a blocking peptide for AChE also obtained from Santa Cruz.

\section{Immunohistochemistry}

Stomachs were excised and dissected as described above, but for immunohistochemical studies both the mucosa and the submucosa were removed. The tunica muscularis was fixed in Zamboni's fixative (4\% paraformaldehyde and 2\% Picric Acid in PBS) for 2 hours at room temperature and then cleared with DMSO (Sigma Aldrich, St. Louis, MO, USA), which was changed every 15 minutes for 1 hour and then washed in phosphate buffered saline (PBS; 0.01M, pH 7.2) at room temperature. After blocking with $1 \%$ bovine serum albumin for 1 hour at room temperature to prevent non-specific binding, tissues were incubated in goat antiAChE polyclonal antibody (E-19, 1:100; Santa Cruz Biotech) with $0.5 \%$ Triton X-100 for 12 hours at $37^{\circ} \mathrm{C}$. Excess antibody was removed by washing with PBS and tissues were incubated in the fluorescent secondary antibody Alexa Fluor 594 anti-goat IgG (1:1000 dilution with PBS; Molecular Probes, Eugene, OR, USA) for 1 hour at room temperature. For double labeling, tissues were incubated again with a second primary antibody (rabbit anti-PGP 9.5 polyclonal antibody; 1:1000; UltraClone, Isle of Wight, UK) and then an alternatively labeled secondary antibody (eg, Alexa Fluor 488 anti-rabbit IgG; 1:1000 dilution with PBS; Molecular Probes). The labeled tissues were mounted with Aquamount mounting media (VWR, Brisbane, CA, USA) and examined with a LSM 510 Meta confocal microscope (Zeiss, Germany). Images were acquired at $\times 20, \times 40$, and $\times 63$ at 1 , 0.4 , and $0.23 \mu \mathrm{m}$ steps respectively. Laser power and gain settings were kept the same, however the confocal aperture varied between $1 \leq 2$ Airy units. All tissues were imaged sequentially, 
to minimize bleed-through of fluorophores. We also attempted to label tissues with antibodies for butyrylcholinesterase (BChE) but were unable to obtain suitable and specific labeling with available antibodies available.

\section{Recording of Intracellular Electrical Activity}

For experiments using single impalements of smooth muscle cells a strip of muscle from the corpus was pinned in a recording chamber lined with Sylgard 184 elastomer (Dow Corning Corp, Midland, MI, USA) with the mucosal aspect of the circular muscle layer facing upwards. For experiments in which dual intracellular recordings were performed, strips of muscle from the corpus through the antrum to the pyloric sphincter (corpus/antrum strip), cut parallel to the longitudinal muscle fibers along the greater curvature, were made and secured in the recording chamber with the mucosal surface of the circular muscle uppermost. A partitioned bath was used in some experiments. Corpus/ antrum strips were threaded through an aperture in a latex barrier before pinning to the Sylgard. For dual recording experiments, 2 microelectrodes were positioned by independent micromanipulators. One electrode was used to impale cells within the corpus region and the other impaled cells within the antrum. In all experiments the muscle strips were constantly perfused with oxygenated Krebs Ringer Buffer $(\mathrm{KRB})$ at $37^{\circ} \mathrm{C}$. Drugs were diluted into this solution to achieve desired concentrations.

Circular muscle cells were impaled with glass microelectrodes filled with a $3 \mathrm{M} \mathrm{KCl}$ solution, which had a resistance of 70-100 M $\Omega$. Transmembrane potentials were measured with high impedance electrometers (WPI Intra 767; World Precision Instruments, Sarasota, FL, USA) and outputs were displayed on a Hitachi VC-6025A oscilloscope (Hitachi Denshi Ltd, Japan). Electrical signals were digitized at $200 \mathrm{~Hz}$ and stored on a PC-style computer using AcqKnowledge (Version 3.5.7.; BIOPAC Systems Inc, Santa Barbara, CA, USA). Electrophysiological experiments were performed in the presence of nifedipine $(1 \mu \mathrm{M})$ to reduce muscle contraction and help maintain impalements and in the presence of L-NNA to reduce neural responses to the major inhibitory transmitter, nitric oxide.

\section{Imaging of Gastric Peristalsis}

Gastric peristalsis was recorded by video imaging of movements of ex vivo intact stomachs and flat-sheet gastric corpus/antrum preparations in vitro. Stomachs were excised and secured in a warmed, oxygenated organ bath. After recording baseline activity of the intact stomachs (containing gastric contents), the stom- achs were opened along the lesser curvature, contents were removed and the mucosa was removed by sharp dissection. The region of the stomach from the orad corpus to the pylorus was pinned as a sheet in a dish lined with Sylgard 184 elastomer (Dow Corning, Midland, MI, USA). Black surface markers (Stampenduous, Anaheim, CA, USA) were placed in a $3 \times 5$ or $3 \times 6$ (circumferential $\times$ longitudinal) grid over the serosal surface of the gastric muscles. The markers were adherent without the need for glue. The dominant contractile pattern of wild type stomachs was a continuous series of peristaltic contractions that began in the corpus and propagated to the pylorus. Video recordings were collected as previously described ${ }^{18}$ using a high definition video camera (DMK31AF03, ImagingSource, Charlotte, NC, USA) connected to a computer using AstroIIDC software (ASC, Calgary, Alberta, Canada) to record QuickTime movies (.mov files) on a Mac OS-based computer (Mac, Apple Co, Cupertino, CA, USA). The tissues were constantly perfused with oxygenated $\mathrm{KRB}$ solution at $37^{\circ} \mathrm{C}$.

\section{Analysis of Gastric Peristalsis Recorded by Video Imaging}

Video images (.mov files) were analyzed using "in-house" software (Volumetry G6a-G8a, G.W.H). Spatio-temporal maps (ST maps) were generated to measure the frequency, velocity and amplitude of peristaltic contractions and to characterize the pattern of motor activity, as previously described. ${ }^{18,22}$ Briefly, images were thresholded to define the outer edges of the stomach which indented as contractile waves passed. The circumferential distance between the cut edges of the tissue was calculated and corresponding ST maps of diameter were generated. Deeper indentations (stronger amplitude of contractions) are indicated by lighter colored pixels on the ST Map. The oral-to-anal distance along the edge of the tissue corresponds to the y-axis of the map. Time is mapped along the $\mathrm{x}$-axis, so the patterns of contraction are portrayed in the ST map as cyclical lighter and darker changes with successive contractions and relaxations, respectively.

Contraction wavefronts were isolated in ST maps using the sum of a series of differential filters to identify positive inflexions ( $\Delta t=0.17-0.34$ seconds). The midpoint of identified wavefronts was calculated from which: (1) the interval, (2) the change in interval from wave-to-wave, (3) instantaneous velocity (using slope of linear regression in $1 \mathrm{~mm}$ span), and (4) the change in instantaneous velocity from wave-to-wave at the same position along the stomach were calculated. The change in interval and instantaneous velocity were used to assess the consistency and sta- 
bility of contraction wave fronts under different conditions and expressed as standard deviation (SD). The percentage of orthograde or retrograde propagating contractions were calculated from instantaneous velocity frequency distributions. Where appropriate both orthograde $\left(\mathrm{iVel}_{\mathrm{o}}\right)$ and retrograde $\left(\mathrm{iVel}_{\mathrm{r}}\right)$ velocities are given.

\section{Drugs and Solutions}

The composition of the KRB used in these studies was (in mM) $118.5 \mathrm{NaCl}, 1.2 \mathrm{MgCl}_{2}, 23.8 \mathrm{NaHCO}_{3}, 1.2 \mathrm{KH}_{2} \mathrm{PO}_{4}$, 11.0 dextrose, and $2.4 \mathrm{CaCl}_{2}$. The $\mathrm{pH}$ of the buffer was 7.3-7.4 when bubbled with $97 \% \mathrm{O}_{2}-3 \% \mathrm{CO}_{2}$ at $37 \pm 0.5^{\circ} \mathrm{C}$. Atropine, carbamylcholine chloride (carbachol; $\mathrm{CCh}$ ), neostigmine bromide, $\mathrm{N} \omega$-Nitro-L-arginine (L-NNA), and nifedipine were purchased from Sigma. Atropine, $\mathrm{CCh}$, and neostigmine bromide were dissolved in water. Nifedipine was dissolved in ethanol. The final bath concentration of both DMSO and ethanol did not exceed $0.1 \%(\mathrm{v} / \mathrm{v})$, and neither solvent had any effect at this concentration. All drugs tested were applied via bath perfusion for 10-20 minutes.

\section{Analysis of Data}

Data are expressed as means $\pm \mathrm{SEM}$. The $\mathrm{n}$ values reported in the text refer to the number of animals from which muscle strips were taken. Frequency data is expressed as cycles per minute (cpm). SigmaStat Statistical Software for Windows version 2.03 (SPSS Science, Chicago, IL, USA) was used for statistical analyses. Before performing tests of significance, data were examined for normality and equal variance to determine whether parametric or non-parametric tests should be employed. Paired and unpaired $t$ tests and one-way ANOVA (repeated measures) followed by multiple comparisons against the control (Tukey's test) were used where appropriate for statistical comparisons. A probability of $P<0.05$ was used as a cut-off for statistical significance. $P$-values quoted for ANOVA are the values for the individual post-hoc test.

\section{Results}

\section{Expression and Localization of Cholinesterases in Gastric Muscles}

Expression of Ache and Bche transcripts in mouse brain (control) and gastric tunica muscularis were identified by RTPCR (Fig. 1A). RT-PCR was performed with Gapdh primers as a control for cDNA integrity. Amplicons of expected sizes con- firmed that the PCR products were representative of RNA and not contaminated with genomic DNA (intron containing amplicons would be much larger). Ache transcripts can be products of alternative splicing, producing three distinct proteins that differ in C-termini. ${ }^{23}$ The primers we used for RT-PCR were designed to amplify a common region of Ache transcripts (exons 2 and 3), which encodes the catalytic domain present in all active AChE variants. Real-time RT-PCR (qPCR) was performed to quantify Ache and Bche mRNA expression in brain and gastric muscles. Ache and Bche transcript expression were calculated from cycle threshold values using the standard curve analysis method and

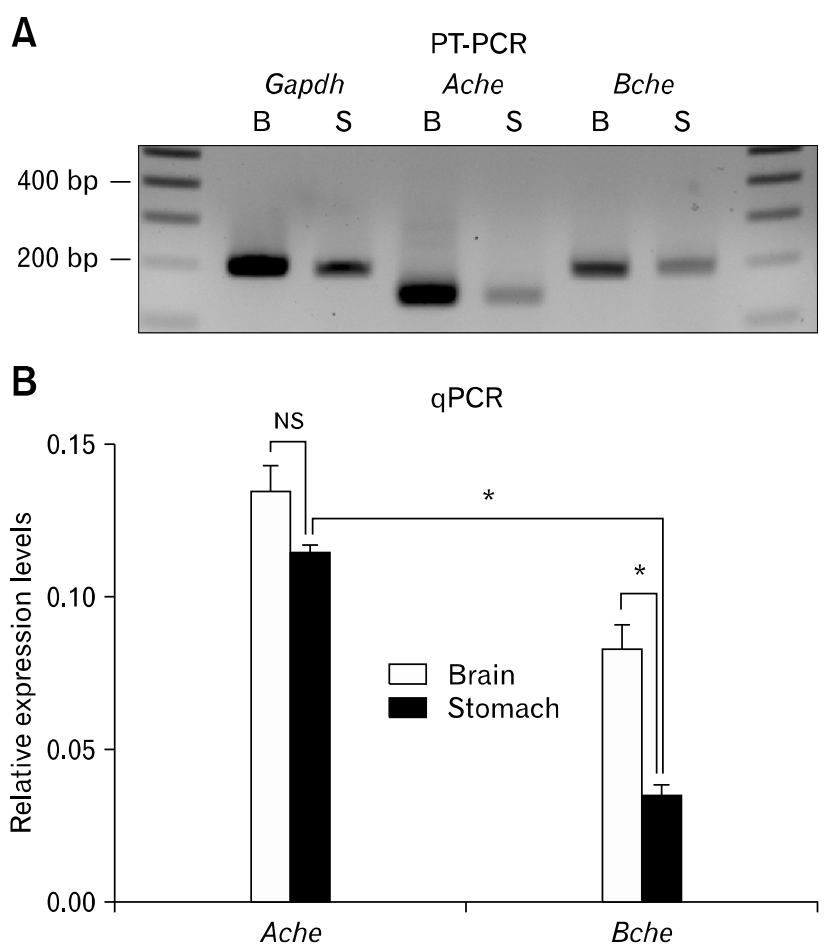

Figure 1. RT-PCR and quantitative (q)PCR analysis of $A$ che and $B$ che expression in murine brain and stomach. (A) It shows RT-PCR of extracts from murine brain and gastric muscles. Ache and Bche are expressed in both tissues. RT-PCR products for Gapdh (180 base pair [bp]), Ache (142 bp) and Bche (190 bp) expressed in brain (B) and stomach (S) were resolved alongside a $100 \mathrm{bp}$ marker. The density of the gels from RT-PCR is not a quantitative representation of relative expression. (B) It shows quantitation of relative expression of $A$ che and $B c h e$ in brain and stomach using real time PCR (qPCR). The expression of $A c h e$ and $B c h e$ transcripts were calculated relative to the expression of endogenous Gapdh transcripts in the same tissues. Data are expressed as means \pm SEM ( $\mathrm{n}=3$ mice). Expression of Ache was as highly expressed in gastric muscles as in brain $(P=0.199)$. Bche was more highly expressed $(*)$ in brain than in gastric muscles $(P<0.001)$, and Ache was more highly expressed (*) in gastric muscles than Bche ( $P$ $<0.001)$. NS, not significant. 
reported relative to Gapdh expression in the same tissues (arbitrary units). Relative expression of AChe (0.135 \pm 0.0077 in brain and $0.115 \pm 0.0020$ in gastric muscles) and Bche $(0.083 \pm$ 0.0078 in brain and $0.045 \pm 0.0031$ in gastric muscles; mean \pm SEM, $\mathrm{n}=3$ mice) mRNAs are shown in Fig. 1B. Bche expression was about $61 \%$ and about $39 \%$ of Ache expression in brain and in gastric muscles, respectively.

Western blotting was performed on homogenates of corpus and antral muscles from $\mathrm{BALB} / \mathrm{c}, W / W^{v}$ and wild type control mice using antibodies specific for AChE. Protein bands for AChE were observed at $68 \mathrm{kDa}$, as expected. The presence of the blocking peptide prevented resolution of the band at $68 \mathrm{kDa}$ confirming the specificity of the antibody (Fig. 2). We detected no significant differences in the expression of $\mathrm{AChE}$ in corpus and antral muscles or in any of the 3 mouse strains tested $(P>0.05$, 1-way ANOVA followed by Tukey's test; $\mathrm{n}=5$ from each strain; Fig. 2).

PCR demonstrated expression of cholinesterases in gastric muscles. Previous studies have suggested that most AChE is bound to the plasma membranes, ${ }^{24}$ and various cells in gastric muscles were considered as potential repositories for $\mathrm{AChE}$, namely, neurons, interstitial cells, and smooth muscle cells. Preliminary studies using single antibody labeling for AChE suggested that neuronal cells may be the predominant site of $\mathrm{AChE}$ expression in gastric muscles. In wildtype and $W / W^{v}$ mice enteric motor neuron processes running parallel to smooth muscle fibres displayed AChE-like immunoreactivity (AChE- LI) and PGP9.5-like immunoreractivity (PGP9.5-LI, Fig. 3A-F). AChE-LI was also expressed in nerve cell bodies in ganglia (Fig. 3G-I). Few nerve bundles labeled with PGP9.5-LI were negative for AChE-LI. When single fibers with discrete varicosities were visualized, AChE-LI was noted along the entire lengths of the axons, in varicose and non-variocose regions of neurons. The density of the neural processes were not significantly different in wildtype and $W / W^{v}$ tissues (ie, $12.17 \pm 0.83$ and $11.33 \pm 0.80$; $\mathrm{n}=3$ each) processes per random $100 \mu \mathrm{M}$ transecting line perpendicular to circular muscle layer bundles, respectively). Antibodies obtained for $\mathrm{BChE}$ produced non-specific labeling, so we were unable to include cellular localization of this protein in this study.

\section{Muscarinic Effects in Murine Corpus}

Although post-junctional muscarinic responses have been documented in murine antrum, ${ }^{5,19}$ responses of the murine corpus have not been characterized. $\mathrm{CCh}(100 \mathrm{nM})$ increased slow wave
A
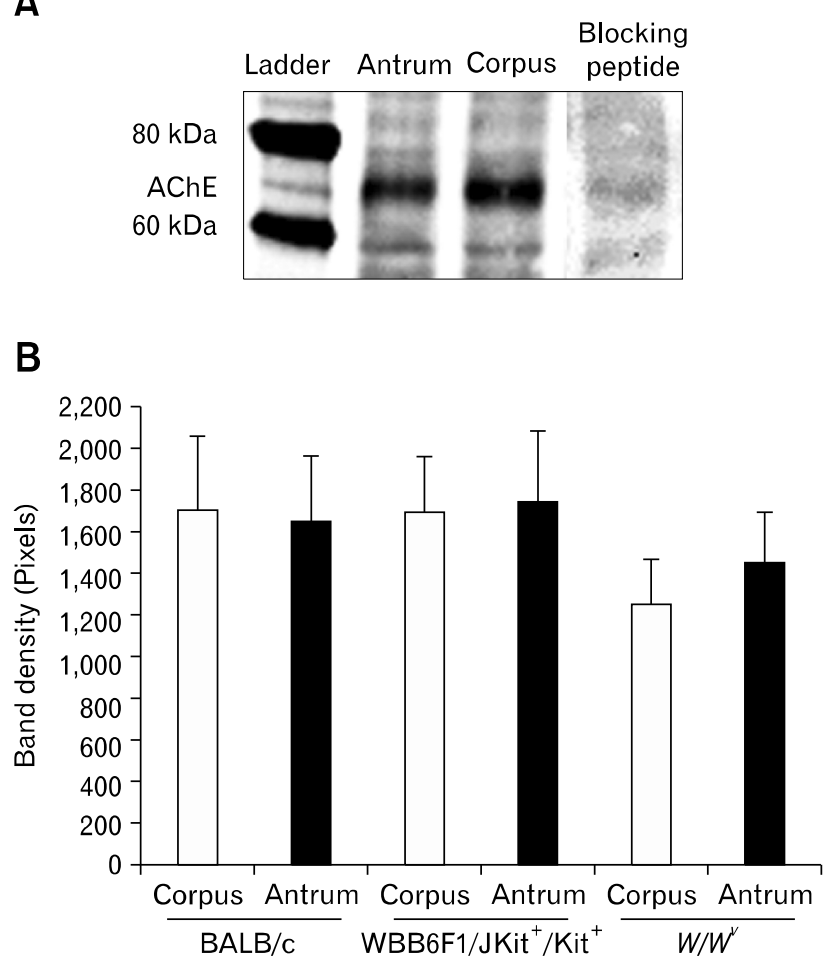

Figure 2. Western blots showing relative expression of acetycholinesterase protein in 3 strains of mice. (A) It shows lanes from Western blots and a ladder showing band at $69 \mathrm{kDa}$. Blocking peptide inhibited immunoblot at this molecular weight. (B) It shows summary of band densities in 3 strains of mice ( $\mathrm{n}=5$ for each strain).

frequency in $\mathrm{BALB} / \mathrm{c}$ corpus muscles (from $7.0 \pm 0.8$ to $9.5 \pm$ $0.9 \mathrm{cpm}$ in the presence of $\mathrm{CCh} ; P<0.05$, Student's paired $t$ test; $\mathrm{n}=8$; Fig. 4A). The chronotropic effects were accompanied by significant depolarization in resting membrane potential (ie, the most negative potential between slow waves depolarized from $-68 \pm 4 \mathrm{mV}$ to $-46 \pm 3 \mathrm{mV}$ in presence of CCh; $P$ $<0.05$ ) and decrease in the amplitude of slow waves (from $28 \pm$ $6 \mathrm{mV}$ to $13 \pm 2 \mathrm{mV}$ in the presence of $\mathrm{CCh}$; both $P<0.05$; Student's paired $t$ test). These effects are similar to the effects of CCh on murine gastric antrum. ${ }^{5,19}$

Sustained electrical field stimulation (EFS; 0.1 milliseconds pulse duration, $150 \mathrm{~V}$ intensity, $5 \mathrm{~Hz}$ frequency) increased slow wave frequency in corpus muscles from $6.2 \pm 0.4$ to $7.4 \pm 0.2$ cpm. This effect was completely abolished by atropine $(100 \mathrm{nM})$ and slow wave frequency was returned to $6.3 \pm 0.4 \mathrm{cpm}$. The increase caused by EFS and block of the effect by atropine were significant (ie, $P<0.05,1$-way ANOVA followed by Tukey's test; $\mathrm{n}=10$; Fig. 4B). In contrast to the effects of bath-applied $\mathrm{CCh}(100 \mathrm{nM})$, muscarinic stimulation via release of transmitter 

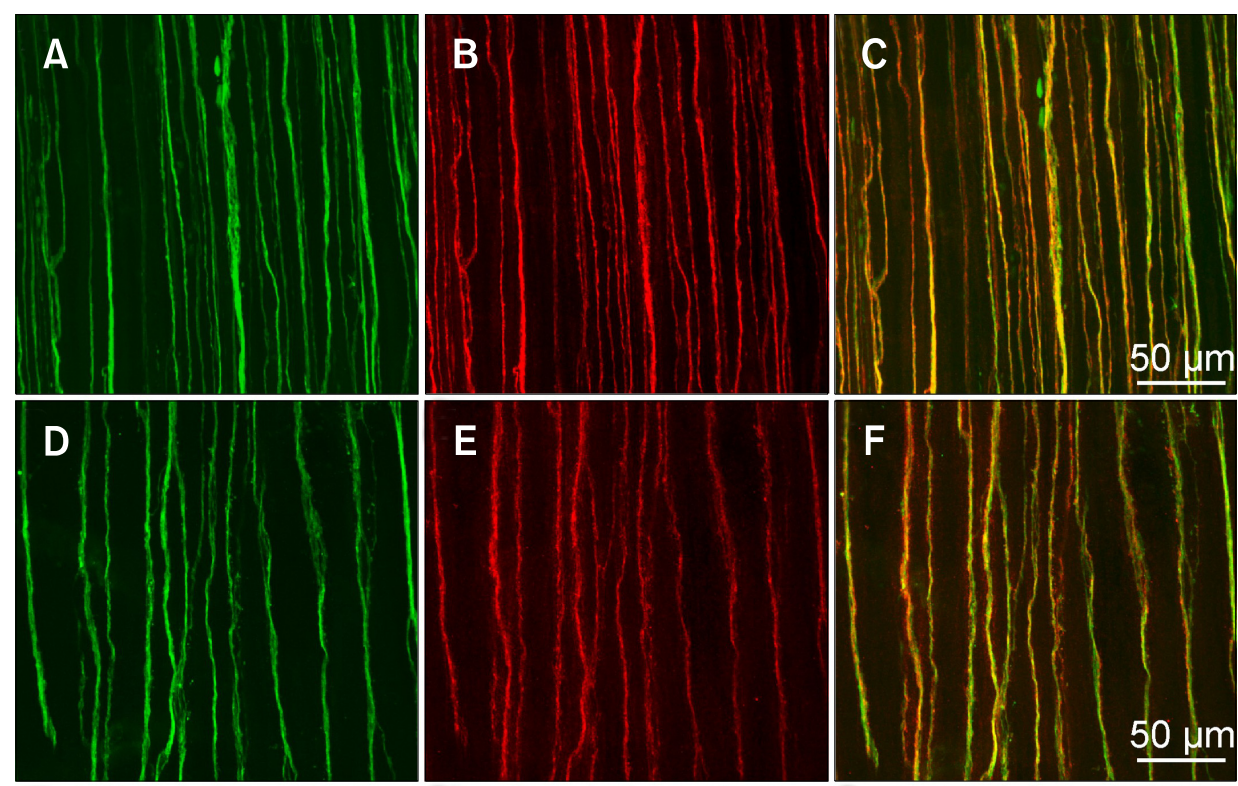

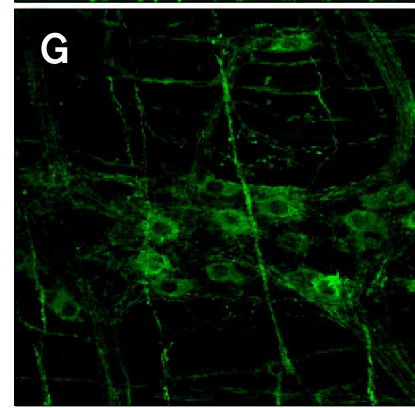

PGP9.5

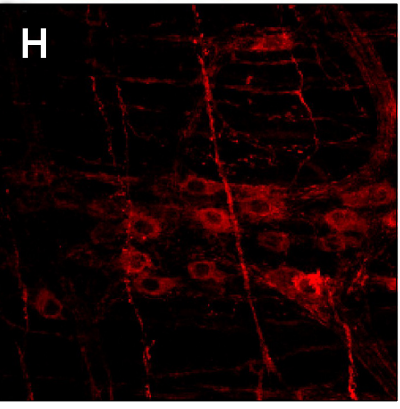

AChE

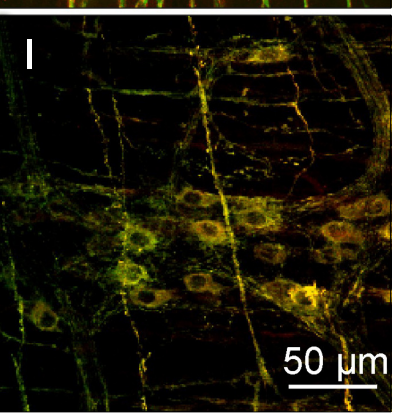

Merge
Figure 3. Localization of acetycholinesterase (AChE) in myenteric neurons and nerve processes in the tunica muscularis of the stomach. Flat mounts of antral muscles were doubled labeled with antibodies against PGP9.5 (ubiquitous neural marker: A and D; G: green) and $\mathrm{AChE}(\mathrm{B}, \mathrm{E}$, and $\mathrm{H}$ : red). C, F, and I are merged files (yellow) demonstrating co-localization of $\mathrm{AChE}$ like immunoreactivity in cells labeled with PGP9.5. A, B, and $\mathrm{E}$ are from $\mathrm{Babl} / \mathrm{c}$ mouse, and $\mathrm{C}, \mathrm{D}$, and $\mathrm{F}$ are from a $W / W^{v}$ mouse. AChE was found in the varicose processes of enteric motor neurons (B and $\mathrm{E}$ ), close to the sites of neurotransmitter release and in the cell bodies within the myenteric plexus (H; BALB/c mouse tissue sample shown). from intrinsic neurons produced no significant effect on resting membrane potential or the amplitude or duration of slow waves.

We have previously shown that neostigmine $(1 \mu \mathrm{M})$ increased slow wave frequency significantly in murine antral muscles, suggesting tonic release of $\mathrm{ACh}$ and stimulation of muscarinic receptors in these muscles (eg, effect blocked by atropine). ${ }^{5}$ In the present study we found that neostigmine $(1 \mu \mathrm{M})$ also increased slow wave frequency in BALB/c murine corpus muscles from 5.8 \pm 0.4 to $7.7 \pm 0.4 \mathrm{cpm}$. The chronotropic effect of neostigmine was reversed by atropine $(100 \mathrm{nM} ; 5.0 \pm 0.2 \mathrm{cpm}$; Fig. $4 \mathrm{C} ; \mathrm{n}=$ 4), TTX (100 nM; $5.7 \pm 0.4 \mathrm{cpm}$; Fig. 4D; $\mathrm{n}=5)$ or hexamethonium ( $100 \mathrm{nM} ; 6.3 \pm 0.4 \mathrm{cpm}$; Fig. 4D; $\mathrm{n}=5$; all changes $P$ $<0.05$; 1-way ANOVA, followed by Tukey's test). In addition to the chronotropic effects, neostigmine also caused significant depolarization of resting membrane potential (ie, from $-66 \pm 2$ $\mathrm{mV}$ to $-55 \pm 4 \mathrm{mV}$ in control and in the presence of neostigmine, respectively; $P<0.05$, 1-way ANOVA, followed by Tukey's test). As with the chronotropic effect, the depolarization was also abolished by atropine $(100 \mathrm{nM}$; to $-63.4 \pm 1.7 \mathrm{mV})$, TTX
$(100 \mathrm{nM}$; to $-63.4 \pm 1.7 \mathrm{mV})$, and hexamethonium (300 nM; to $-63.4 \pm 1.7 \mathrm{mV} ; P>0.05,1$-way ANOVA followed by Tukey's test).

During repetitive EFS (0.1 milliseconds, $150 \mathrm{~V}, 5 \mathrm{~Hz})$, which produced small, but significant, chronotropic effects on slow wave pacemakers, neostigmine $(1 \mathrm{M})$ caused further increase in slow wave frequency (i.e. from $7.0 \pm 0.7$ in control to $7.9 \pm 0.5 \mathrm{cpm}$ with EFS, and to $8.6 \pm 0.9 \mathrm{cpm}$ with EFS and neostigmine). The enhancements in slow wave frequency with EFS and EFS and neostigmine were reversed by atropine (100 nM; $7.3 \pm 0.5 \mathrm{cpm} ; P<0.05$ as compared with control, 1-way ANOVA, followed by Tukey's test; Fig. 5). As described above, release of ACh from neurons caused no effect on resting membrane potential or slow wave amplitude, however, when neostigmine was added, resting membrane potential depolarized from $-68 \pm 4.3 \mathrm{mV}$ to $-42 \pm 5.6 \mathrm{mV}$ and slow wave amplitude decreased from $29 \pm 4 \mathrm{mV}$ to $14 \pm 3 \mathrm{mV}$ (both $P<0.05$, 1 -way ANOVA, followed by Tukey's test). These changes were abolished by atropine (eg, resting membrane potential restored to 
A

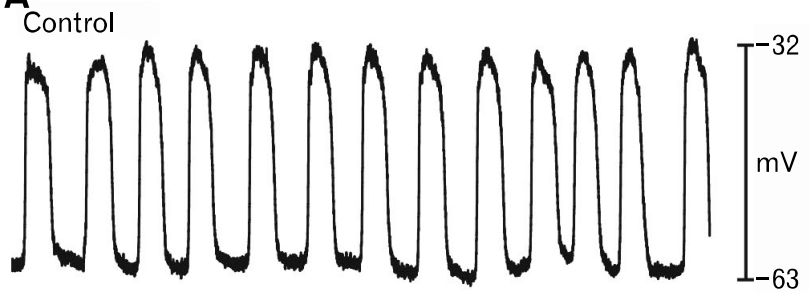

Carbachol (100 nM)

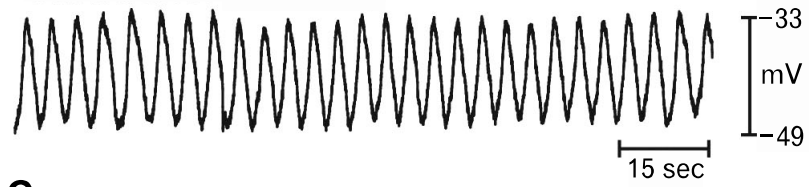

C

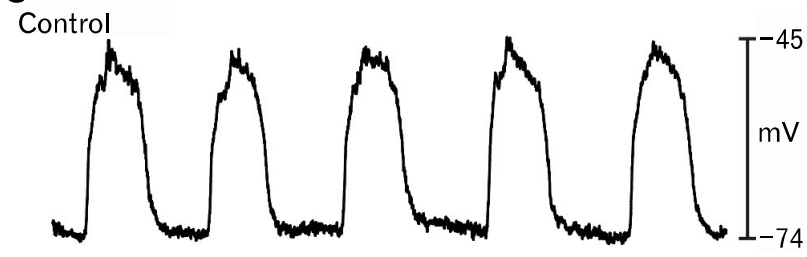

Neostigmine $(1 \mu \mathrm{M})$

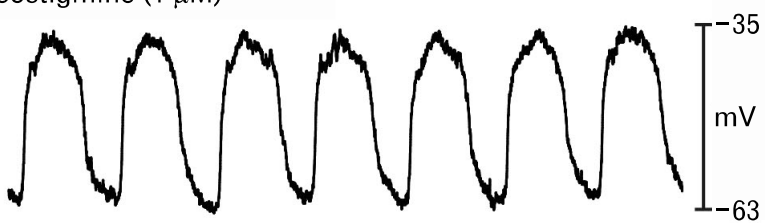

Neostigmine $(1 \mu \mathrm{M}) \&$ atropine $(100 \mathrm{nM})$

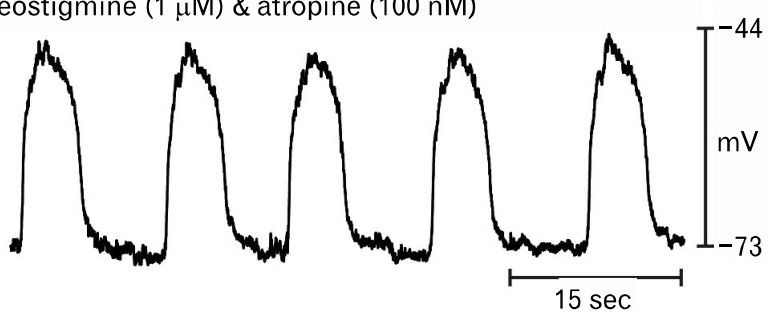

B

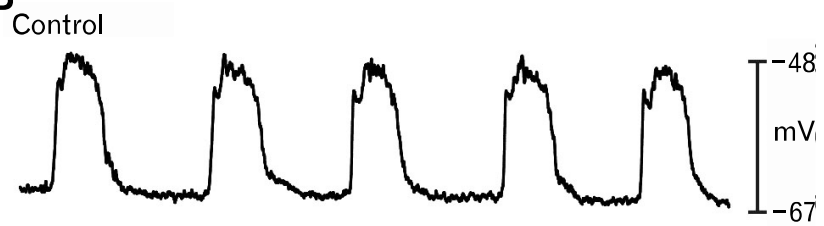

Sustained EFS $(5 \mathrm{~Hz})$

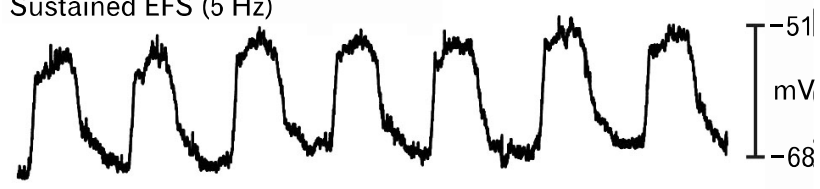

EFS $(5 \mathrm{~Hz})$ and atopine $(100 \mathrm{nM})$

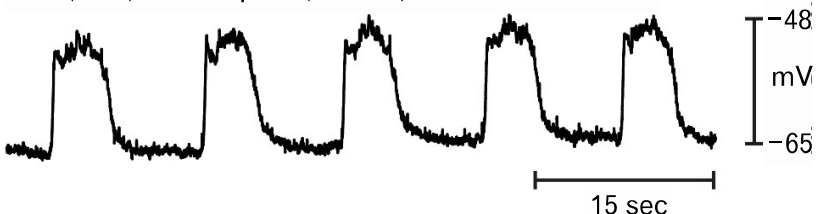

D

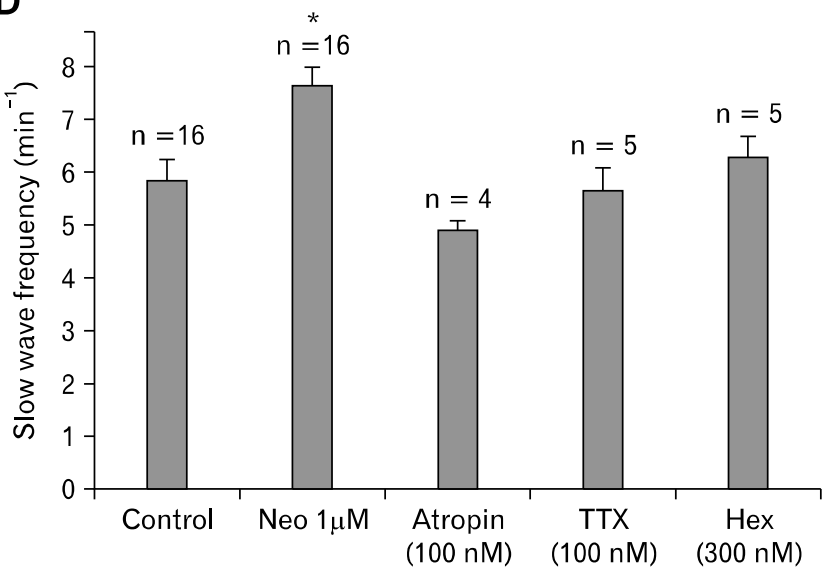

Figure 4. Effects of cholinergic stimulation on electrical activity of the corpus. (A) Slow waves from corpus circular muscle under control conditions (Krebs-Ringer bicarbonate solution [KRB] perfusion) and after addition of carbachol (CCh; $100 \mathrm{nM})$. CCh depolarized resting membrane potential and increased the frequency of slow waves. (B) Slow waves from another corpus muscle are shown before (upper trace), during a period of electrical field stimulation (EFS; $5 \mathrm{~Hz}$; 0.1 milliseconds pulses; middle trace), and after addition of atropine during EFS (100 nM; bottom trace). EFS enhanced the frequency of slow waves without significant change in resting membrane potential. (C) Slow waves recorded from corpus are shown in control conditions (top trace) after treatment with neostigmine ( $1 \mu \mathrm{M}$; middle trace), and after atropine was added in the presence of neostigmine (100 $\mathrm{nM}$; bottom trace). (D) It shows a summary of the effects of neostigmine on slow wave frequency (numbers of muscles are shown above each test condition: asterisk (*) indicates $P<0.05$ compared to control). Atropine, tetrodotoxin, and hexamethonium also reduced the elevation in slow wave frequency caused by neostigmine. Data are means \pm SEM.

$-73 \pm 7.3 \mathrm{mV}$; slow wave amplitude to $29 \pm 3.7 \mathrm{mV}$ ).

\section{Muscarinic Effects in Corpus/Antrum Muscles}

Corpus and antrum work together in vivo and slow wave generated in the corpus propagate through the antrum to the py- loric sphincter. The small size of murine stomachs made it possible to create strips of muscle corresponding to most of the length of the slow wave propagation pathway (ie, orad corpus to the terminal antrum), and we tested responses of these muscles to muscarinic stimulation. Dual intracellular recordings were made so we could monitor responses in corpus and antral cells simultane- 
A Control (KRB)

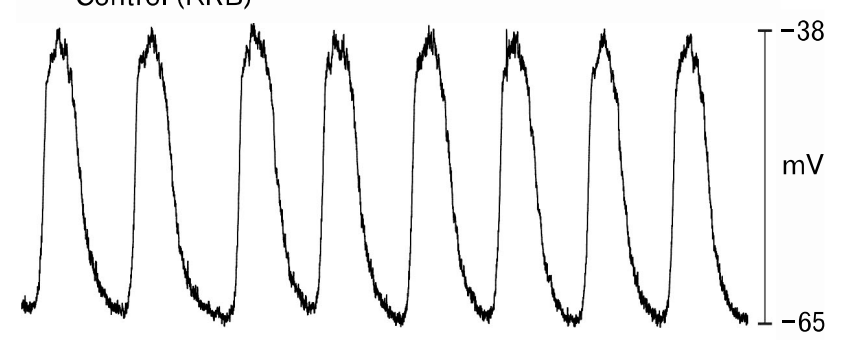

B Sustained EFS $(5 \mathrm{~Hz})$

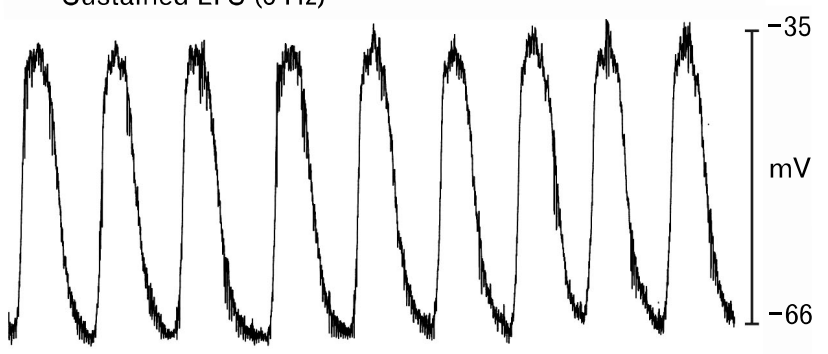

C EFS $(5 \mathrm{~Hz})$ and neostigmine $(1 \mu \mathrm{M})$

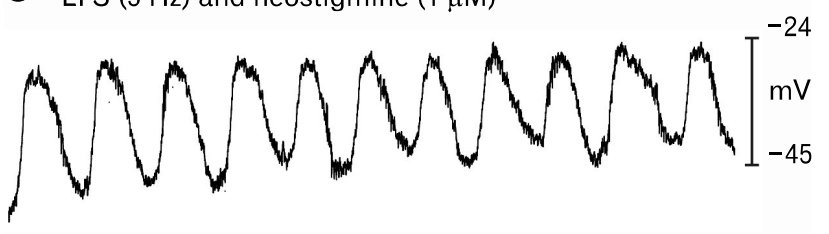

D EFS, NEO and atropine (100 $\mathrm{nM})$

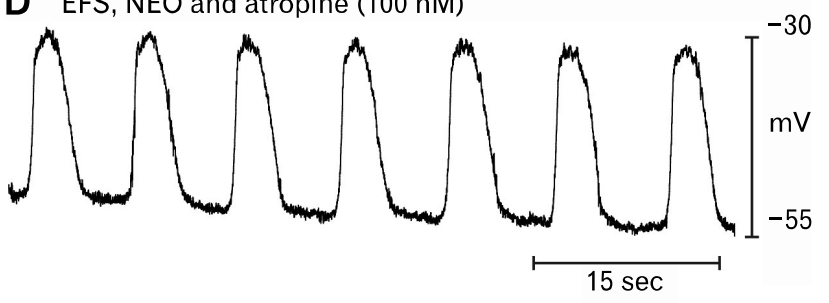

Figure 5. Electrical field stimulation (EFS) before and after addition of neostigmine. (A) It shows slow wave activity from a BALB/c corpus muscle under control conditions and in (B) during EFS (0.1 milliseconds, $150 \mathrm{~V}, 5 \mathrm{~Hz}$ ). An increase in slow wave frequency was noted with EFS, but no depolarization. (C) It shows a second period of EFS after addition of neostigmine $(1 \mu \mathrm{M})$. In addition to the increase in slow wave frequency a marked depolarization was noted after neostigmine. (D) It shows that the chronotropic effects of EFS were blocked by atropine $(100 \mathrm{nM})$. Membrane potential was also partially restored by atropine.

ously. CCh $(100 \mathrm{nM})$ significantly increased slow wave frequency in the corpus and antrum (Fig. 6; from $8.4 \pm 0.5$ to 11.5 $\pm 0.8 \mathrm{cpm}$ and from $8.3 \pm 0.6$ to $11.7 \pm 0.8 \mathrm{cpm}$ before and in the presence of $\mathrm{CCh}$ in the corpus and antrum, respectively; $\mathrm{n}=$ 6; $P<0.05$; paired $t$ tests;). From 2-point recording, we could not detect any loss of coordination between the corpus and antrum in response to $\mathrm{CCh}$. As described in previous experiments,
A Control (KRB)

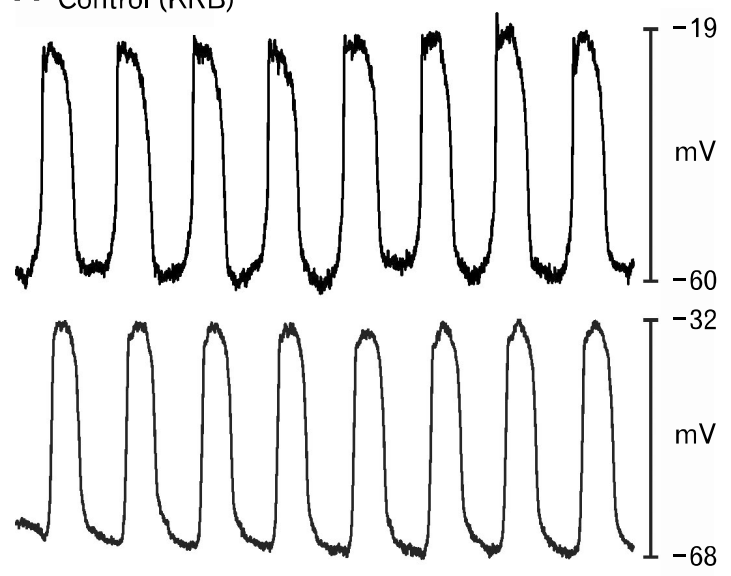

B $\operatorname{cch}(100 \mathrm{nM})$
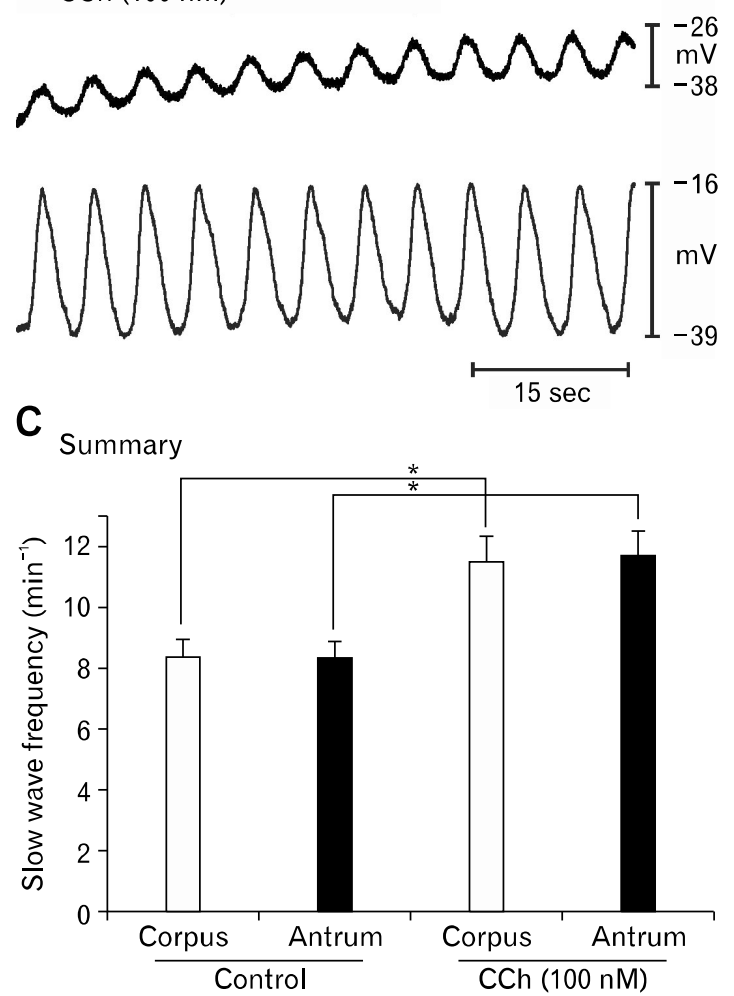

Figure 6. Effects of carbachol (CCh) on corpus/antrum muscle strips. (A) Slow wave activity recorded under control conditions from BALB/c muscle strip retaining corpus/antrum structure and coupling. Corpus and antrum recordings, made simultaneously, are the top and bottom traces, respectively, in each panel. (B) Excerpt of activity during continuous impalements after addition of $\mathrm{CCh}(100 \mathrm{nM})$. Note increase in slow wave frequency and depolarization. No evidence of breakdown in coupling between corpus and antrum was observed. (C) Summary of the effects of CCh in 6 experiments. Asterisk ( $*$ denotes significant changes from control $(P<0.05$ by paired Student's $t$ test). 
A Control (KRB)
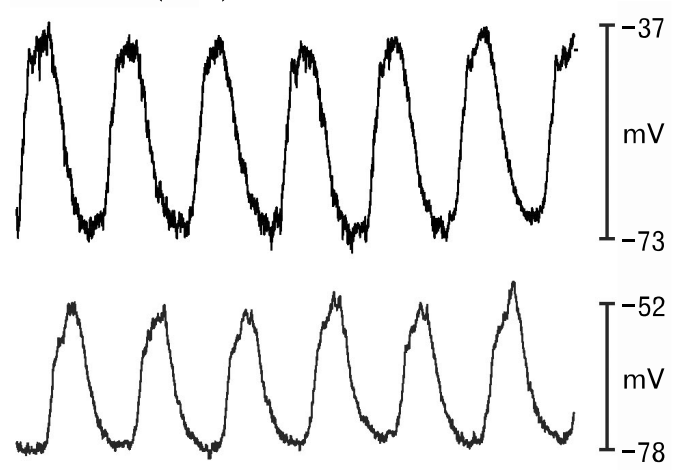

B

Neostigmine $(1 \mu \mathrm{M})$
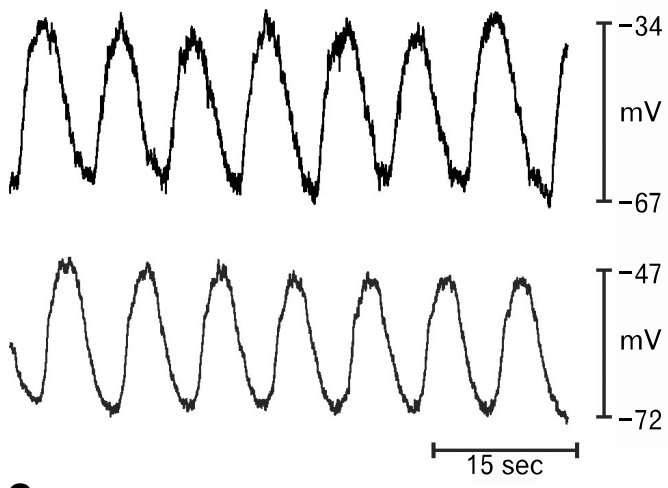

C summary

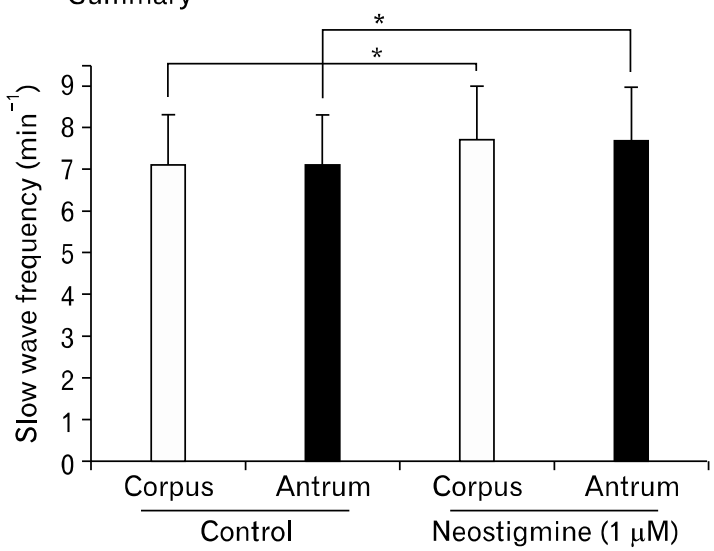

Figure 7. Slow wave activity is coupled in corpus/antrum muscle strips. (A) Shows slow wave activity recorded under control conditions from a $\mathrm{BALB} / \mathrm{c}$ muscle strip containing corpus and antrum portions of the stomach. Coupling between corpus and antrum was retained in these muscle strips. Recordings were made from cells impaled in the corpus and antrum simultaneously (top and bottom traces, respectively, in each panel). (B) Excerpt of activity during continuous impalements after addition of neostigmine $(1 \mu \mathrm{M})$. Note increase in slow wave frequency and depolarization. No evidence of breakdown in coupling between corpus and antrum was observed. (C) Summary of the effects of neostigmine in 6 experiments. Asterisk (*) denotes significant changes from control $(P<0.05$ by paired Student's $t$ test). the chronotropic effects of $\mathrm{CCh}$ were accompanied by membrane depolarization in both regions of muscle. Corpus depolarized from $-72 \pm 1.0 \mathrm{mV}$ to $-50 \pm 7.6 \mathrm{mV}$ and antrum depolarized from $-65 \pm 3.1 \mathrm{mV}$ to $51 \pm 4.6 \mathrm{mV}$, before and in the presence of CCh respectively ( $\mathrm{n}=6 ; P<0.05$, paired $t$ tests). Slow wave amplitude also decreased, in association with depolarization, from $34 \pm 4.0 \mathrm{mV}$ and $19 \pm 3.0 \mathrm{mV}$ in the corpus and from $32.7 \pm$ $3.8 \mathrm{mV}$ to $22.0 \pm 3.6 \mathrm{mV}$ in the antrum, before and in the presence of CCh, respectively ( $\mathrm{n}=6 ; P<0.05$, paired $t$ tests).

Neostigmine $(1 \mu \mathrm{M})$ also increased slow wave frequency in cells of the corpus and antrum (eg, slow waves in the corpus increased from $7.2 \pm 1.4$ and $7.8 \pm 1.3 \mathrm{cpm}$ and slow waves in the antrum increased from $7.2 \pm 1.1$ and $7.8 \pm 1.3 \mathrm{cpm}$ before and in the presence of neostigmine $(P<0.05$, paired t tests; $\mathrm{n}=6$; Fig. 7). However, uncoupling between corpus and antrum was not detectable with 2 point electrical recording. Membrane potentials in both regions depolarized (from $-72 \pm 2.9 \mathrm{mV}$ to -53 $\pm 3.5 \mathrm{mV}$ in the corpus and $-76 \pm 3.1 \mathrm{mV}$ to $-51 \pm 5.9 \mathrm{mV}$ in the antrum before and in the presence of neostigmine $(P<$ $0.05)$.

These experiments suggested that the antrum and corpus are both capable of responding equally to cholinergic stimuli applied to the whole tissue. The next question we addressed was to determine what happens if one specific region (either antrum or corpus) of the stomach tissue is stimulated selectively. Stimulating electrodes were placed across the muscle in the corpus and antral ends of the corpus/antrum strips of muscle, and repetitive EFS ( 0.1 milliseconds, $150 \mathrm{~V}, 5 \mathrm{~Hz}$ ) was applied selectively to either region. When EFS was applied selectively to the corpus slow waves frequencies were increased in the corpus and antrum (from $8.1 \pm 0.6$ to $9.3 \pm 0.5 \mathrm{cpm}$ in the corpus and $8.1 \pm 0.5$ to $9.2 \pm$ $0.6 \mathrm{cpm}$ in the antrum in control and during EFS, respectively ( $\mathrm{n}$ $=6 ; P<0.05$, paired $t$ tests; Fig. 8A-C). These data suggested that the antrum was able to follow corpus pacemakers when frequency was increased modestly by EFS. When repetitive EFS ( 0.1 milliseconds, $150 \mathrm{~V}, 5 \mathrm{~Hz}$ ) was applied selectively to the antral end of the muscle strip there was no gain in frequency in either region (corpus: $7.7 \pm 0.3$ and $7.6 \pm 0.3 \mathrm{cpm}$; antrum: 7.7 \pm 0.2 and $7.5 \pm 0.3 \mathrm{cpm}$ in control and with EFS, respectively; $P>0.05, \mathrm{n}=5$; Fig. 8D-F), in spite of the fact that this level of stimulation was able to elevate frequency in isolated antral muscle strips. $^{5}$

We also tested selected application of neostigmine to the corpus and antrum regions of the muscle using a partitioned bath in which the 2 regions could be independently perfused. ${ }^{18}$ Addition 
A

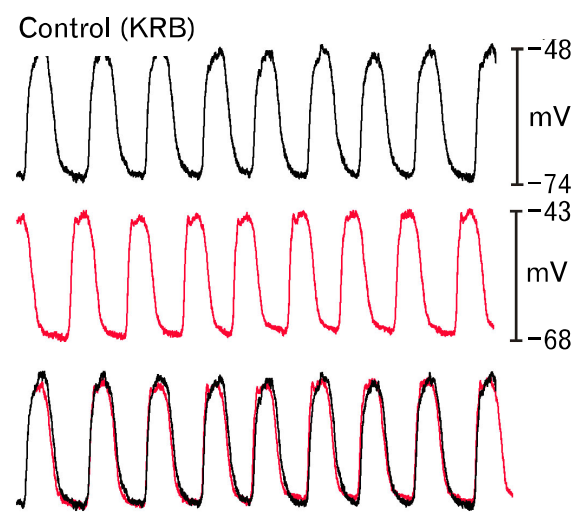

B EFS corpus $(5 \mathrm{~Hz})$
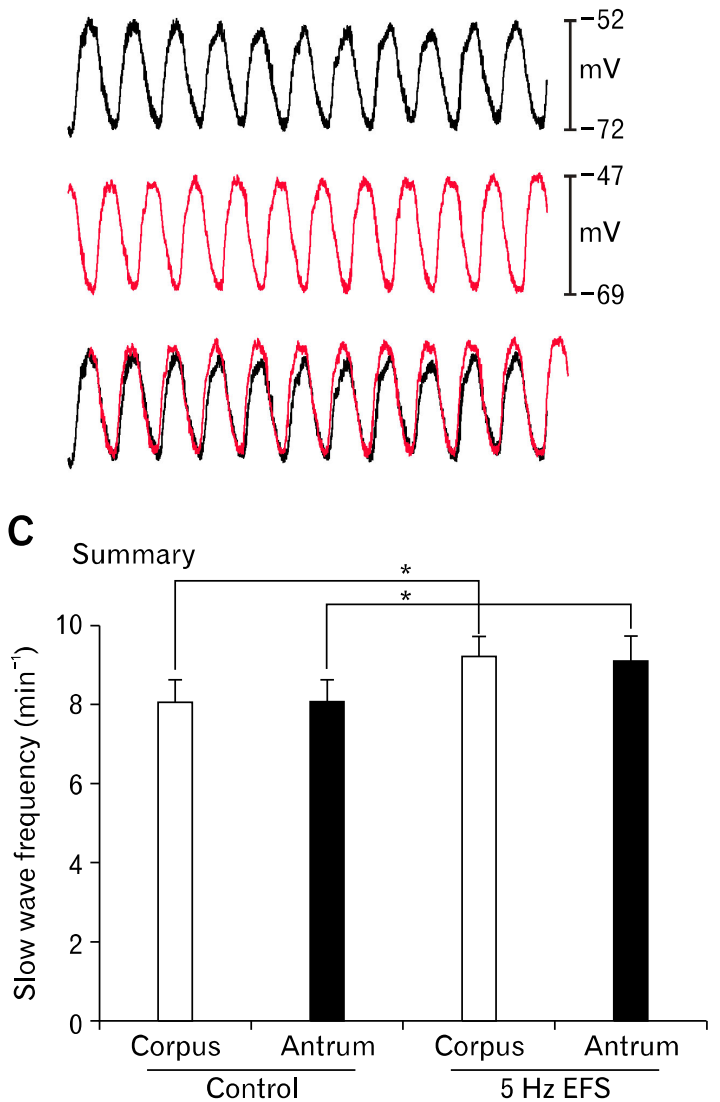

D Control (KRB)

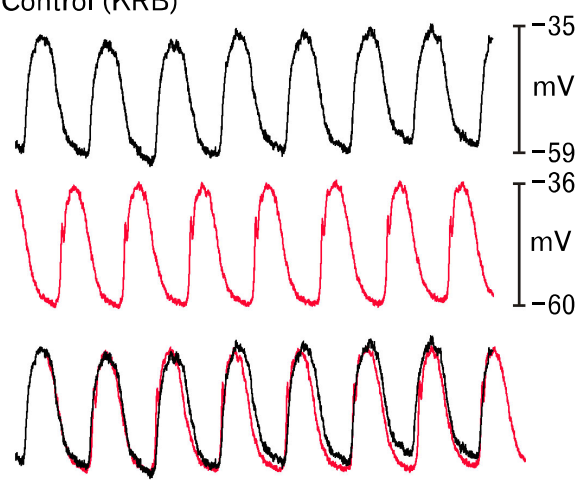

E EFS antrum (5 Hz)
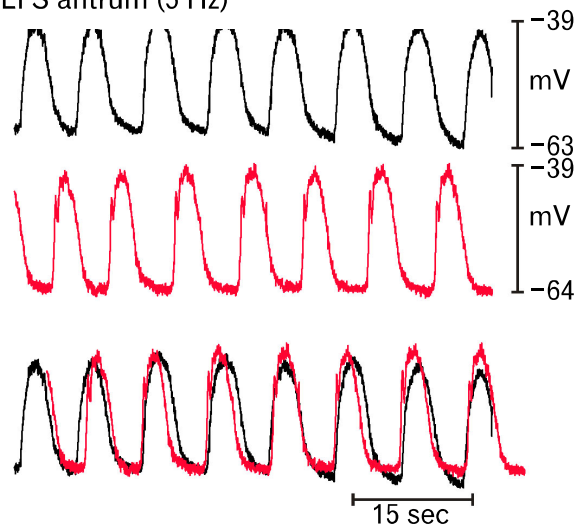

F

Summary

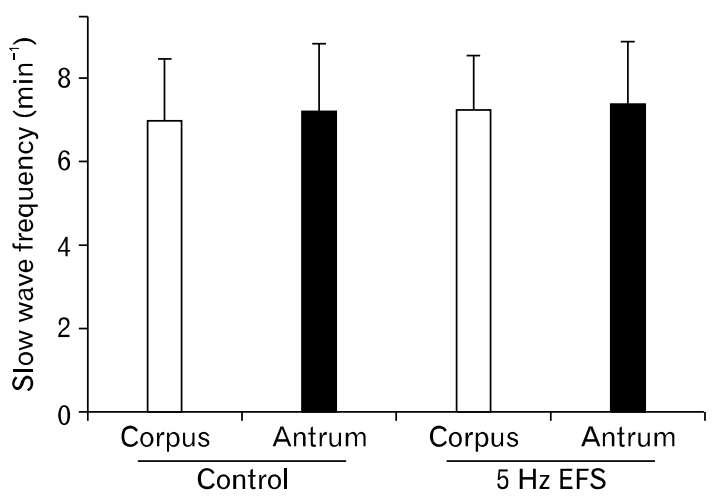

Figure 8. Effects of selective corpus or antrum electrical field stimulation (EFS) on slow wave activity in intact gastric corpus/antrum muscle strips. (A) Slow waves were recorded from corpus (black traces) and antrum (red traces) cells under control conditions. Superimposed traces show 1:1 coupling between slow wave activities in both regions. (B) Shows effects of selective EFS (0.1 milliseconds, $150 \mathrm{~V}, 5 \mathrm{~Hz})$ of corpus. Experiments were conducted in partitioned chamber to reduce possible stray current stimulation of antrum. The superimposed traces demonstrate no loss of coupling during corpus EFS. (C) Summary of the effects of corpus EFS in 6 experiments. Asterisk ( $*$ ) denotes significant changes from control $(P<0.05$ by paired Student's $t$ test). (D) Slow waves were recorded from corpus (black traces) and antrum (red traces) cells under control conditions. (E) Shows effects of selective EFS (0.1 milliseconds, $150 \mathrm{~V}, 5 \mathrm{~Hz}$ ) of antrum. The superimposed traces demonstrate no loss of coupling during antral EFS. (F) Summary of the effects of antral EFS in 5 experiments. There was no significant change in frequency noted in either region from antral EFS $(P>$ 0.05 by paired Student's $t$ test). 

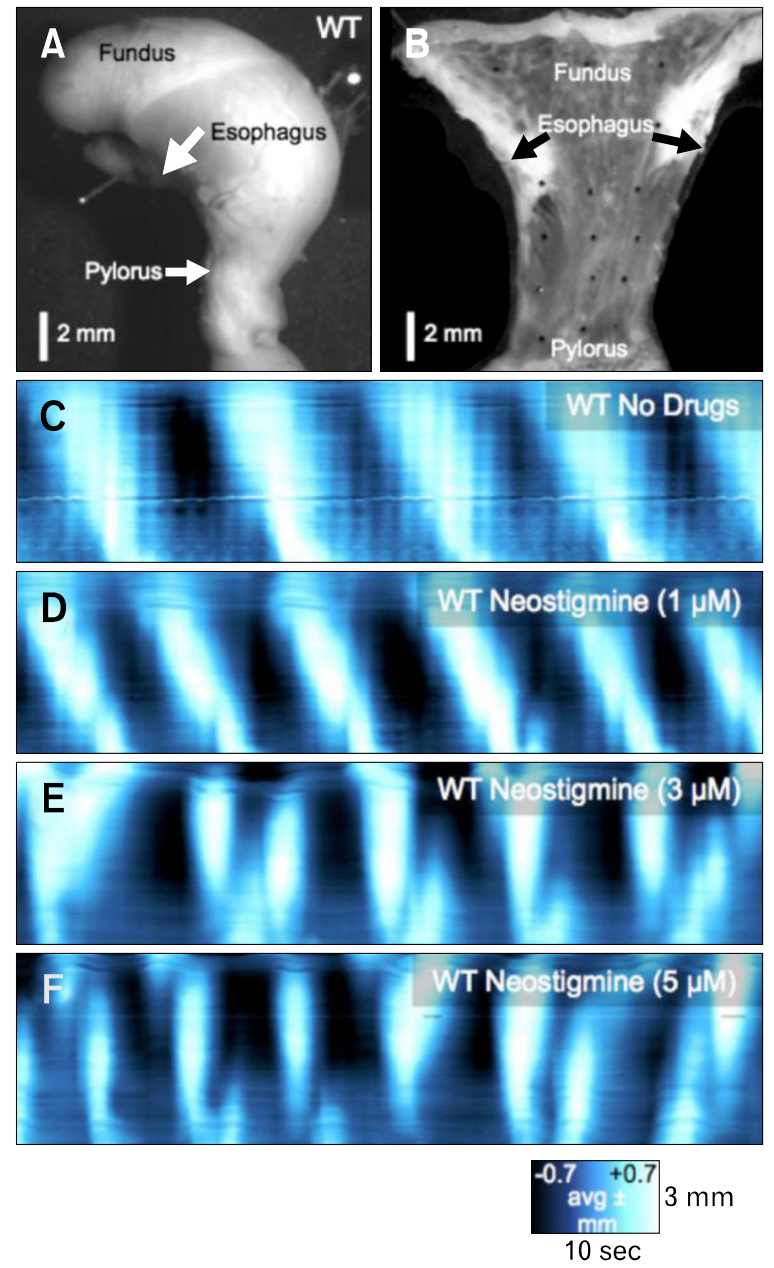
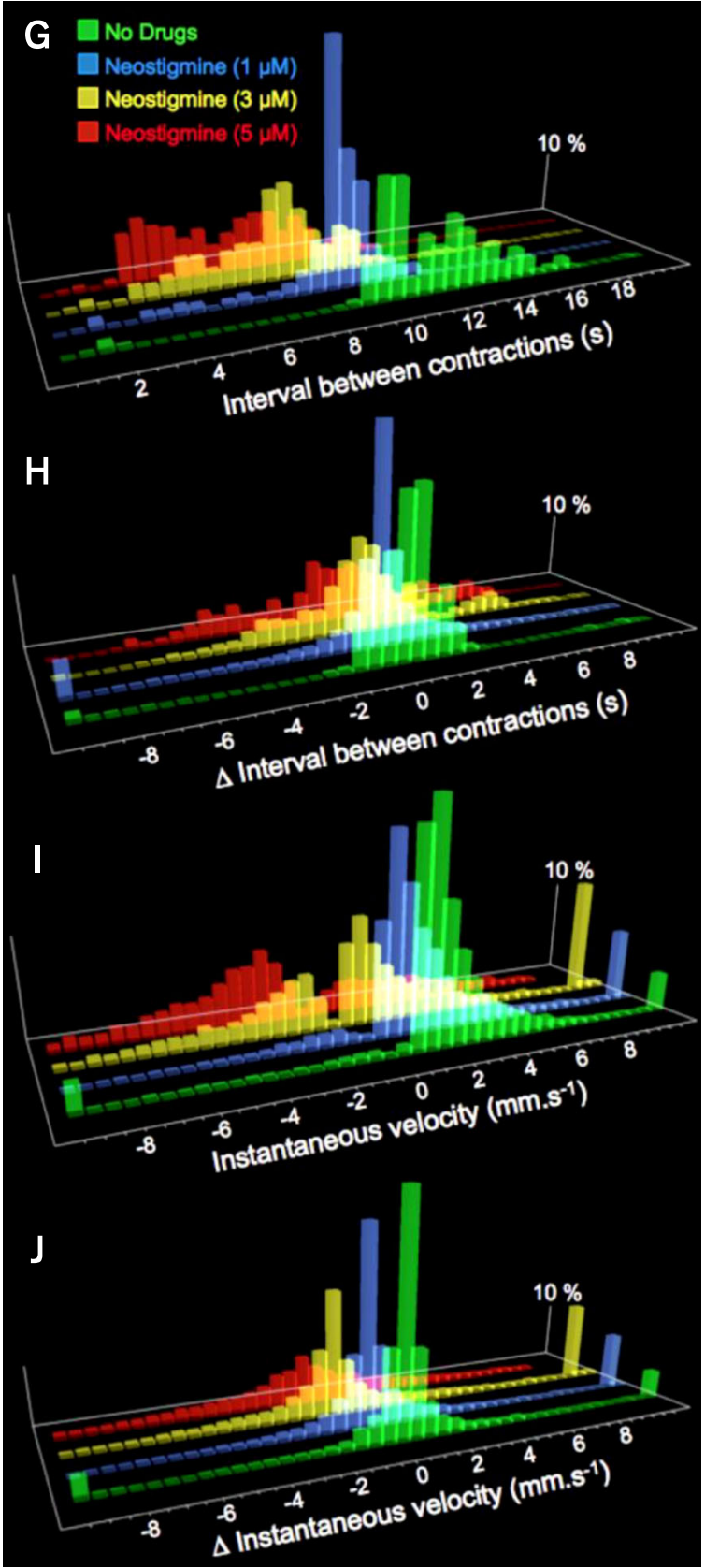

Figure 9. Effects of neostigmine on gastric peristaltic contractions. (A) It shows an intact, isolated stomach. The stomach was cut lengthwise along the lesser curvature and the mucosa was removed. The resulting sheet of tunica muscularis was pinned out as a flat-sheet preparation as shown in (B). (C) Spatio-temporal map of contractions running along the edges of the flat-sheet preparation showing proximal-to-distal propagation of peristaltic contractions (white left to right sloping bands). In this experiment the contractions originated in the orad corpus and propagated coherently to the pylorus at a frequency of about $5 \mathrm{cpm}$. (D) Addition of neostigmine $(1 \mu \mathrm{M})$ increased the frequency and amplitude of antral peristaltic waves. Higher concentrations of neostigmine $(3 \mu \mathrm{M}[\mathrm{E}]$ and $5 \mu \mathrm{M}[\mathrm{F}]$ ) caused aberrations in the pattern and direction and distance of propagation of peristaltic contractions. $(\mathrm{G})$ It shows frequency histograms of the shortening interval (ie, denoting an increase in frequency) with increasing doses of neostigmine (1-5 $\mu \mathrm{M})$. The temporal stability of antral contractions is shown in $(\mathrm{H})$ where higher doeses of neostigmine (3-5 $\mu \mathrm{M})$ markedly increase the variance in interval from wave-to-wave. Frequency histograms of instantaneous velocity (I) show an increasing prevalence of retrogradely propagating contractions (negative velocities) with higher doses of neostigmine (3-5 $\mu \mathrm{M})$. The change in instantaneous velocity at the same position along the stomach from wave-to-wave is shown in $(\mathrm{J})$ and shows increased variability with higher doses of neostigmine (3-5 $\mu \mathrm{M})$. 
of neostigmine $(1 \mu \mathrm{M})$ to the corpus side of the partition increased slow wave frequency in both the corpus and antrum (from $6.2 \pm 0.6$ to $8.6 \pm 0.6 \mathrm{cpm}$ in the corpus and from $6.2 \pm$ 0.6 to $8.6 \pm 0.6 \mathrm{cpm}$ in the antrum before and in the presence of neostigmine, respectively ( $\mathrm{n}=6 ; P<0.05$; data not shown). As with EFS, these data suggest that the antrum is able to be entrained by the corpus when the slow wave frequency in the dominant pacemaker area increases. In contrast, addition of neostigmine to the antral chamber did not increase overall slow wave frequency $(n=6)$.

\section{Effects of Neostigmine on Gastric Motility}

Two-point intracellular electrical recording from muscle strips failed to resolve the effects of muscarinic stimulation and $\mathrm{AChE}$ on the coordination of gastric slow waves, however due to the excitatory nature of these stimuli, it was difficult to maintain impalements when higher concentrations of drugs were tested. Therefore, we made flat sheet preparations from the entire murine stomach (Fig. 9A and 9B) and used imaging techniques to provide high-resolution visualization of the coordination of peristaltic contractions as these events spread from the corpus to the pylorus (Fig. 9C-9F).

\section{Wild type BALB/c mice}

In control recordings, contractions were initiated in the orad corpus at a stable frequency $(5.30 \pm 0.45 \mathrm{cpm}$, Fig. 9C and 9G: $\Delta$ interval sd $= \pm 1.0$ second: Fig. $9 \mathrm{C}$ and $9 \mathrm{H}$ ) and propagated in a linear and consistent pattern toward the pylorus (93\% orthograde direction: $\mathrm{iVel}_{\mathrm{o}}=1.87 \pm 0.66 \mathrm{~mm} / \mathrm{sec}$, Fig. 9C and 9I; $\Delta \mathrm{iVel}= \pm 1.3 \mathrm{~mm} / \mathrm{sec}$, Fig. $9 \mathrm{C}$ and $9 \mathrm{~J})$. Neostigmine was added cumulatively to final bath concentrations of 1,3 , and $5 \mu \mathrm{M}$ (Fig. 9D-9F). At $1 \mu \mathrm{M}$, the frequency of antral peristaltic contractions was increased $(7.10 \pm 0.61 \mathrm{cpm}$ : $\Delta$ interval $\mathrm{SD} \pm 1.0$ seconds) and antral peristaltic waves still propagated coherently in the orthograde direction (87\% orthograde direction: $\mathrm{iVel}_{\circ}=$ $2.23 \pm 0.48 \mathrm{~mm} / \mathrm{sec}$, Fig. 9D and 9I; $\Delta \mathrm{iVel}= \pm 1.8 \mathrm{~mm} / \mathrm{sec}$, Fig. 9D and 9J). Increasing neostigmine to $3 \mu \mathrm{M}$ increased frequency to $8.59 \pm 1.18 \mathrm{cpm}(\Delta$ interval $\mathrm{SD} \pm 2.3$ seconds; $P<$ $0.05)$, and contractions became disorganized and irregular and direction and velocity of propagation were unstable $(60 \%$ orthograde direction: $\mathrm{iVel}_{\mathrm{o}}=2.51 \pm 0.86 \mathrm{~mm} / \mathrm{sec}, \mathrm{iVel}_{\mathrm{r}}=-3.06 \pm$ $0.92 \mathrm{~mm} / \mathrm{sec}$, Fig. $9 \mathrm{E}$ and 9I; $\Delta \mathrm{iVel}= \pm 2.9 \mathrm{~mm} / \mathrm{sec}$, Fig. $9 \mathrm{E}$ and $9 \mathrm{~J}]$ ). Often numerous initiation sites emerged throughout the gastric sheets and contractions failed to propagate through the antrum. At $5 \mu \mathrm{M}$ neostigmine initiation sites of contractions were highly irregular throughout the muscle sheets $(10.32 \pm$ $1.74 \mathrm{cpm}: \pm \Delta$ interval $\mathrm{SD} \pm 3.5$ seconds; $P<0.05)$ and the propagation was largely retrograde $(43 \%$ orthograde direction: $\mathrm{iVel}_{\mathrm{o}}=4.04 \pm 0.99 \mathrm{~mm} / \mathrm{sec}, \mathrm{iVel}_{\mathrm{r}}=-3.30 \pm 0.93 \mathrm{~mm} / \mathrm{sec}$, Fig. $9 \mathrm{~F}$ and 9I; $\Delta \mathrm{iVel}= \pm 4.8 \mathrm{~mm} / \mathrm{sec}$, Fig. 9F and 9J) with poor directional stability and premature termination of propagating contraction.

\section{Electrical stimulation}

To enhance ACh release from motor neurons, we tested low frequency transmural electrical field stimulation (EFS; 0.4 milliseconds, $70 \mathrm{~V}, 3 \mathrm{~Hz}$ : electrodes across distal antrum) in the presence of L-NNA (100 $\mu \mathrm{M}$; to block inhibitory neurotransmission). With only L-NNA present, the pattern of antral peristaltic contractions was largely unchanged by electrical stimulation in 4 of 6 preparations in terms of frequency and velocity. In the other 2 preparations, sustained contraction was observed for about 20 seconds after the commencement of EFS, followed by return of largely normal antral peristaltic contractions. EFS in the presence of $1 \mu \mathrm{M}$ neostigmine resulted in unstable, uncoordinated, high frequency contractile activity, often with large sustained contractions immediately after the commencement of electrical simulation (4 of 6 ). At 3 and $5 \mu \mathrm{M}$ neostigmine, the amplitude of contractions was enhanced and instabilities were magnified. Blocking cholinergic muscarinic receptors with atropine $(1 \mu \mathrm{M})$ abolished the response to electrical stimulation. EFS caused a slow constriction of the preparation, but the pattern, frequency and velocity were unchanged (Fig. 10).

\section{$\boldsymbol{W} / \boldsymbol{W}^{v}$ mice}

The pattern of contractions in the antrum of $W / W^{v}$ mice was unstable, particularly with respect to the amplitude. Instead of a single sustained contraction that propagated smoothly towards the pylorus, contractions in gastric sheets of $W / W^{v}$ mice were higher in frequency, shorter duration and lower in amplitude contractions than in control (Fig. 11). These general activities were superimposed on slower cyclic activity. Addition of neostigmine $(1 \mu \mathrm{M})$ increased the inherent instability of gastric contractions in muscles sheets of $W / W^{v}$ mice and unstable frequencies, sites of initiation, incoherent propagation and increased prevalence of uncoordinated contractions were observed. Higher doses of neostigmine (3-5 $\mu \mathrm{M}$; Fig. 11E \& F) displayed similar characteristics as observed with $1 \mu \mathrm{M}$ neostigmine, but with increased amplitude of contractions. 

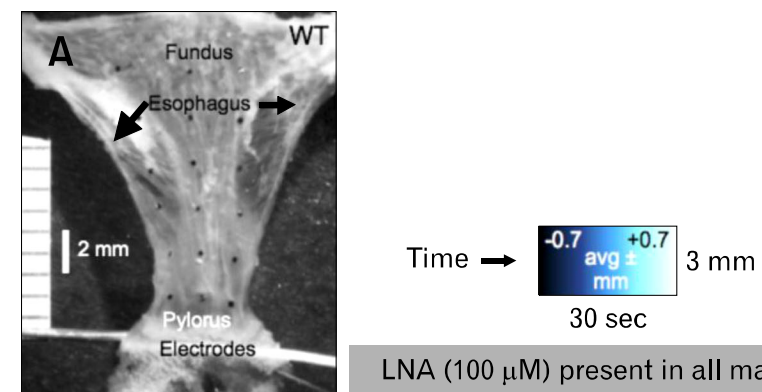

LNA $(100 \mu \mathrm{M})$ present in all maps
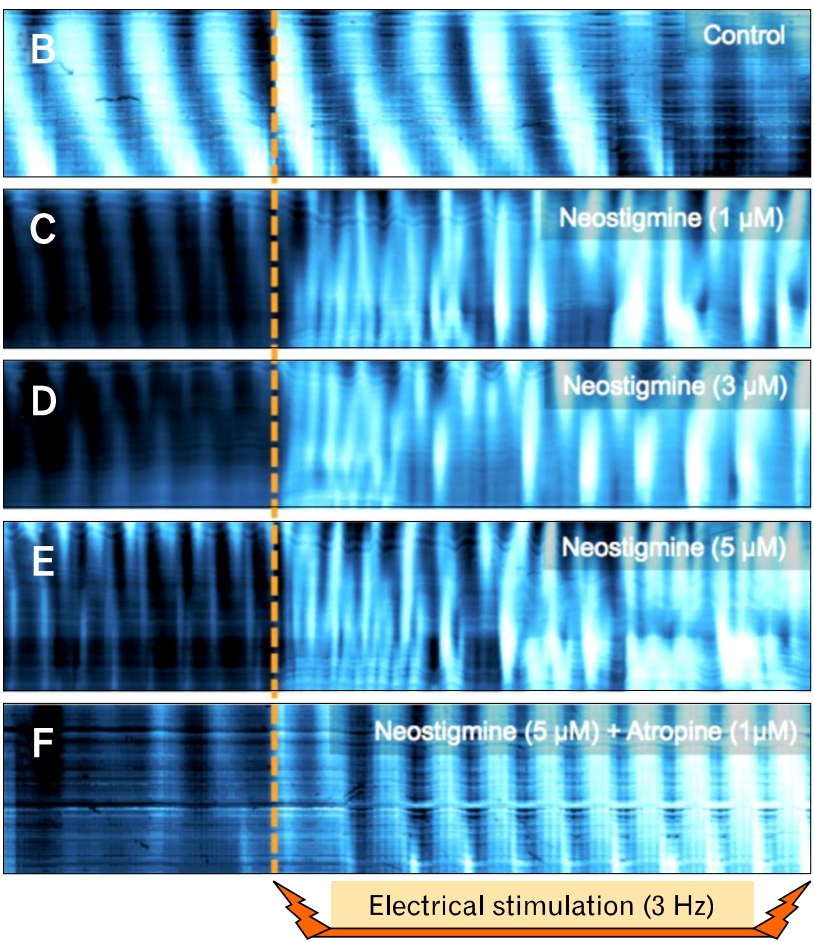

Figure 10. Effects of electrical stimulation on gastric peristaltic contractions after blocking acetycholinesterase activity. (A) It shows a flatsheet preparation with electrodes positioned across the pylorus. $\mathrm{N} \omega$ Nitro-L-arginine (L-NNA; $100 \mu \mathrm{M}$ ) was present throughout the experiment to block inhibitory responses to electrical stimulation. With only L-NNA present, electrical stimulation (0.4 milliseconds, $70 \mathrm{mV}, 3$ $\mathrm{Hz}$ ) had no observable effect on the frequency, amplitude or propagation characteristics of antral peristaltic contractions (B). Addition of neostigmine (1-5 $\mu \mathrm{M}$ : see $\mathrm{C}$-E) increased basal contraction frequency and caused a dramatic high frequency burst of erratic contractions during electrical stimulation. Blocking cholinergic muscarinic receptors with atropine $(1 \mu \mathrm{M})$ while neostigmine $(5 \mu \mathrm{M})$ was present prevented the high frequency bursts of contractions (F).

\section{Discussion}

In this study we showed the influence of constitutive cholinesterases in regulating gastric electrical and contractile functions. We found transcripts of both $\mathrm{AChE}$ and $\mathrm{BChE}$ in gastric
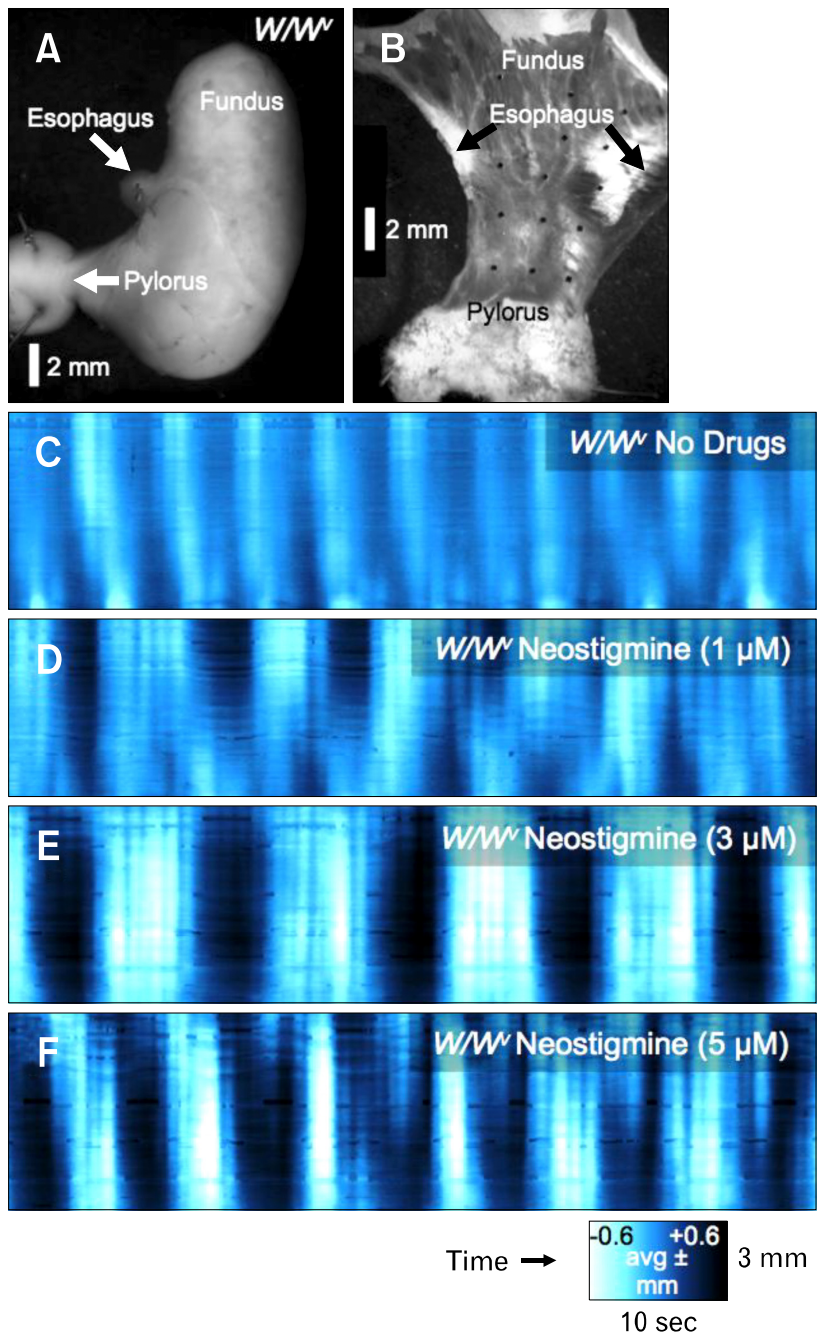

Figure 11. Effects of neostigmine on contractile activity in $W / W^{v}$ mice. (A) It shows a stomach from a $W / W^{v}$ mouse that was dissected to form a flat-sheet preparation (B). With no drugs present, peristaltic contractions were abnormal, consisting of 2-3 pulsatile contractions simultaneously over large areas of the antrum $(\mathrm{C})$. Neostigmine increased the amplitude and duration of the train of pulsatile contractions (D-F).

muscles, but neostigmine, the cholinesterase inhibitor we chose for these studies, is similarly effective on both enzymes. ${ }^{25} \mathrm{AChE}$ transcripts were expressed robustly in gastric muscles, nearly to the same extent as in brain tissues, as indicated by quantitative PCR. Immunohistochemical labeling showed the dominant localization of $\mathrm{AChE}$ protein to be enteric motor neurons, which course through the tunica muscularis. The first level of importance of $\mathrm{AChE}$ in gastric motor activity is that this enzyme metabolizes ACh that is released by tonic activity of excitatory motor neurons. Background release of ACh could potentially have negative effects on the slow wave frequency gradient in the stomach. In a 
previous study we reported that the antral slow wave frequency increased from 3.1 to 4.3 by treatment with neostigmine. ${ }^{5}$ In the present study we found that neostigmine $(1 \mu \mathrm{M})$ also increased slow waves in the corpus from 5.8 to $7.7 \mathrm{cpm}$. We tested whether the increase in antral slow wave frequency could result in uncoupling and failure for corpus pacemakers to dominate, however, this did not occur in wildtype muscles at this low concentration of neostigmine. Thus, there appears to be a safety factor in which positive chronotropic effects of muscarinic stimulation can be imposed throughout the phasic regions of the stomach without interfering with the proximal to distal spread of slow waves. Higher concentrations of neostigmine caused aberrant motor patterns that included ectopic sites of contractile initiation and disruption in the normal propagation of gastric peristalsis from corpus to antrum. Patterns of contraction that were both arrhythmic and anti-peristaltic were observed. Already aberrant patterns of contraction in $W / W^{v}$ stomachs were also affected by neostigmine, creating repetitive, short duration contractions that nearly abolished periods of relaxation between contractions.

$\mathrm{AChE}$ inhibitors decrease metabolism of ACh released from enteric neurons. ${ }^{26}$ Blocking metabolism of ACh increases the availability of $\mathrm{ACh}$ and probably the effective distance over which ACh can diffuse from excitatory nerve terminals to affect postjunctional receptors. A result of preserving $\mathrm{ACh}$ in the tunica muscularis should be enhanced binding of muscarinic receptors that exert ionotropic and chronotropic effects in gastric muscles. Our observations support this hypothesis. We observed enhanced chronotropic effects in both corpus and antral muscles and the force of contractile activity was manifest in increased gastric movements. Attempts have been made to exploit the increased contractile force elicited by inhibiting AChE as a therapy for post-operative ileus, ${ }^{27}$ refractory constipation induced by opiates, ${ }^{28}$ and intestinal pseudo-obstruction. ${ }^{29}$ Unfortunately, diarrhea and nausea are prevalent complicating side effects of AChE inhibitors. ${ }^{30}$ Increasing the force of contractions might contribute to a "prokinetic" effect, but as the current study indicates, the $\mathrm{AChE}$ inhibitor did not enhance normal gastric motility or preserve motor patterns important for gastric emptying. Studies of the enhancement in contractile force by cholinesterase inhibitors ${ }^{31}$ do not go far enough in establishing a rationale for the use of these compounds as therapeutic agents. Our studies showing how coordinated peristaltic contractions are affected by neostigmine provide a possible explanation for the gastric side effects of AChE inhibitors; aberrant motor patterns and disruption in gastric peristalsis might impede gastric emptying and lead to nausea.

ACh released from motor neurons appears to be largely confined to the close junctions between varicosities and ICC, ${ }^{32}$ and the relatively high expression of cholinesterases may be the key factor limiting broader diffusion of $\mathrm{ACh}$ through the interstitium. We provided evidence previously that inhibition of cholinesterases results in overflow of the transmitter to smooth muscle receptors. ${ }^{32}$ It is well known that muscarinic stimulation of smooth muscle cells activates non-selective cation conductance(s) via binding to muscarinic receptors and mobilization of $\mathrm{G}$ proteins. ${ }^{33-36}$ Stimulation of ICC by ACh has chronotropic effects on pacemaker activity. ${ }^{19}$ Thus, when $\mathrm{ACh}$ is released from nerve terminals and stimulates mainly ICC, chronotropic effects are elicited, however if the transmitter diffuses to smooth muscle cells, depolarization would be expected to develop. Our data support the following concept: (1) CCh added to solutions bathing muscles reaches a broad base of muscarinic receptors expressed by ICC and smooth muscle cells and possibly other cell types in the enteric nervous system and tunica muscularis. Stimulation of receptors on many cells results in depolarization and chronotropic effects. (2) EFS causes only chronotropic effects, suggesting ACh released from nerve terminals reaches and has effects mainly through ICC. (3) inhibition of AChE converts responses to EFS to responses more typical of bath application: chronotropic effects and depolarization. These data suggest that $\mathrm{ACh}$ released from enteric motor neurons is normally very efficiently metabolized near the sites of release and sites of action, and this limits the binding of extra-juctional muscarinic receptors on smooth muscle cells. This concept is consistent with previous findings in which post-junctional cholinergic responses were largely missing in $W / W^{v}$ mice (ie, muscles lacking most intramuscular ICC and synaptic contacts with enteric motor neurons), but when cholinesterase inhibitors were applied, slowly developing and relatively long-lasting post-junctional muscarinic responses were noted in wildtype and $W / W^{v}$ gastric muscles, ${ }^{32}$ suggesting overflow of transmitter to smooth muscle receptors. Another study recently showed evidence for compartmentalization of neurotransmitter in gastric muscles because different post-junctional pathways were activated by $\mathrm{CCh}$ added to bath solutions vs $\mathrm{ACh}$ released from neurons. $^{37}$

At the onset of this study we considered that disruption in gastric peristalsis might result from cholinesterase inhibition due to the increase in antral frequency caused by these agents. Dominance of antral pacemakers by corpus pacemakers depends upon a distinct frequency gradient in which the intrinsic fre- 
quency of corpus pacemakers is 6-7 cpm vs $3 \mathrm{cpm}$ in the antrum. We reasoned that raising the intrinsic frequency of antral pacemakers might be enough to interfere with the dominance of the corpus pacemakers. We found, however, that cholinesterase inhibitors also had chronotropic effects in the corpus, and similar increases in slow wave frequency were observed in both antral and corpus cells. With 2 intracellular electrical recordings at 2 sites (one each in the corpus and antrum) we were unable to detect "functional uncoupling" between regions of the stomach by treatment with $1 \mu \mathrm{M}$ neostigmine. Contractions were too great to maintain impalements when higher concentrations of this drug were tested. Recording electrical activity by extracellular array electrodes was thought in the past to be a more effective method for detecting breakdown in electrical continuity between regions of the stomach. ${ }^{38-40}$ However, recordings via this technique are due largely to movement artifacts rather than to valid electrophysiological recordings of membrane currents (slow waves). ${ }^{41}$ For this reason we employed motility imaging so we could record the progress of gastric peristaltic contractions unambiguously. These studies clearly demonstrated development of functional uncoupling and disruption of gastric peristalsis in response to cholinesterase inhibitors.

At the present time we cannot conclude that functional uncoupling in response to cholinesterase inhibitors occurs as a result of increased intrinsic antral pacemaker frequency. Previous studies have shown that relatively minor depolarization (about 10 $\mathrm{mV}$ ) of the ICC/smooth muscle syncytium results in failure of slow waves to actively propagate in gastric muscles. ${ }^{42}$ This is because active propagation of slow waves depends upon activation of a voltage-dependent $\mathrm{Ca}^{2+}$ conductance, ${ }^{43}$ and this conductance would be inactivated sufficiently to block propagation by the level of depolarization accomplished by inhibition of AChE. Thus, depolarization could be the dominant cause of functional uncoupling by inhibitors of AChE. Further experiments will be necessary to clearly test this hypothesis.

In summary, cholinesterase inhibitors are potentially useful as a means to elicit more forceful contractions by augmenting cholinergic excitatory drive on gastrointestinal muscles. However, these compounds also affect the frequency and coordination of slow wave propagation, resulting in functional uncoupling in the stomach and disordered gastric peristalsis. The full effects of AChE inhibitors were not fully detected by 2 points of intracellular electrical recording, but were highly evident when contractile patterns were observed via imaging techniques. These data suggest that rather extreme gastric motor disorders may be ex- tremely difficult to detect by single or double point electrical recording unless frequency patterns become grossly irregular. Our data also suggest that efficient metabolism of $\mathrm{ACh}$ is an extremely important regulator of gastric peristalsis. Loss or inhibition of effective cholinesterase activity could result in major gastric motor dysfunction. Our findings may explain some of the gastrointestinal-related side effects experienced by patients taking cholinesterase inhibitors for Alzheimer's Disease and other neurodegenerative, neuromuscular or mental disorders.

\section{Acknowledgements}

The authors are grateful to Yulia Bayguinov and the Molecular and Morphology Core laboratory (Core C) that is part of a Program Project Grant (P01 DK41315).

\section{References}

1. Schemann M, Rohn M, Michel K. Motor control of the stomach. Eur Rev Med Pharmacol Sci 2008;12(suppl 1):41-51.

2. Dickens EJ, Hirst GD, Tomita T. Identification of rhythmically active cells in guinea-pig stomach. J Physiol 1999;514(Pt 2):515-531.

3. Ordög T, Ward SM, Sanders KM. Interstitial cells of cajal generate electrical slow waves in the murine stomach. J Physiol 1999;518(Pt 1):257-269.

4. el-Sharkawy TY, Szurszewski JH. Modulation of canine antral circular smooth muscle by acetylcholine, noradrenaline and pentagastrin. J Physiol 1978;279:309-320.

5. Forrest AS, Ordög T, Sanders KM. Neural regulation of slow-wave frequency in the murine gastric antrum. Am J Physiol Gastrointest Liver Physiol 2006;290:G486-G495.

6. Ordög T, Baldo M, Danko R, Sanders KM. Plasticity of electrical pacemaking by interstitial cells of Cajal and gastric dysrhythmias in W/W mutant mice. Gastroenterology 2002;123:2028-2040.

7. Burns AJ, Herbert TM, Ward SM, Sanders KM. Interstitial cells of Cajal in the guinea-pig gastrointestinal tract as revealed by c-Kit immunohistochemistry. Cell Tissue Res 1997;290:11-20.

8. Ishikawa K, Komuro T, Hirota S, Kitamura Y. Ultrastructural identification of the c-kit-expressing interstitial cells in the rat stomach: a comparison of control and Ws/Ws mutant rats. Cell Tissue Res 1997;289:137-143.

9. Burns AJ, Lomax AE, Torihashi S, Sanders KM, Ward SM.. Interstitial cells of Cajal mediate inhibitory neurotransmission in the stomach. Proc Natl Acad Sci USA 1996;93:12008-120013.

10. Song G, David G, Hirst S, Sanders KM, Ward SM. Regional variation in ICC distribution, pacemaking activity and neural responses in the longitudinal muscle of the murine stomach. J Physiol 2005; 564(Pt 2):523-540.

11. Horiguchi K, Semple GS, Sanders KM, Ward SM. Distribution of pacemaker function through the tunica muscularis of the canine gastric antrum. J Physiol 2001;537(Pt 1):237-250.

12. Hirst GD, Edwards FR. Electrical events underlying organized myo- 
genic contractions of the guinea pig stomach. J Physiol 2006;576(Pt 3):659-665.

13. Won KJ, Sanders KM, Ward SM. Interstitial cells of Cajal mediate mechanosensitive responses in the stomach. Proc Natl Acad Sci USA 2005;102:14913-14918.

14. Beckett EA, McGeough CA, Sanders KM, Ward SM. Pacing of interstitial cells of Cajal in the murine gastric antrum: neurally mediated and direct stimulation. J Physiol 2003;553(Pt 2):545-559.

15. Chen JD, Pan J, McCallum RW. Clinical significance of gastric myoelectrical dysrhythmias. Dig Dis 1995;13:275-290.

16. Telander RL, Morgan KG, Kreulen DL, Schmalz PF, Kelly KA, Szurszewski JH. Human gastric atony with tachygastria and gastric retention. Gastroenterology 1978;75:497-501.

17. Ordög T, Takayama I, Cheung WK, Ward SM, Sanders KM. Remodeling of networks of interstitial cells of Cajal in a murine model of diabetic gastroparesis. Diabetes 2000;49:1731-1739.

18. Forrest AS, Hennig GW, Jokela-Willis S, Park CD, Sanders KM. Prostaglandin regulation of gastric slow waves and peristalsis. Am J Physiol Gastrointest Liver Physiol 2009;296:G1180-G1190.

19. Kim TW, Koh SD, Ordög T, Ward SM, Sanders KM. Muscarinic regulation of pacemaker frequency in murine gastric interstitial cells of Cajal. J Physiol 2003;546:415-425.

20. Szurszewski JH. Mechanism of action of pentagastrin and acetylcholine on the longitudinal muscle of the canine antrum. J Physiol 1975; 252:335-361.

21. Bazalakova MH, Blakely RD. The high-affinity choline transporter: a critical protein for sustaining cholinergic signaling as revealed in studies of genetically altered mice. Handb Exp Pharmacol 2006: 525-544.

22. Hennig GW, Costa M, Chen BN, Brookes SJ. Quantitative analysis of peristalsis in the guinea-pig small intestine using spatio-temporal maps. J Physiol 1999;517(Pt 2):575-590.

23. Massoulié $\mathbf{J}$. The origin of the molecular diversity and functional anchoring of cholinesterases. Neurosignals 2002;11:130-143.

24. Silman I, Futerman AH. Modes of attachment of acetylcholinesterase to the surface membrane. Eur J Biochem 1987;170:11-22.

25. Atack JR, Yu QS, Soncrant TT, Brossi A, Rapoport SI. Comparative inhibitory effects of various physostigmine analogs against acetyland butyrylcholinesterases. J Pharmacol Exp Ther 1989;249:194202.

26. Appleyard ME, Smith AD. Secretion of acetylcholinesterase and butyrylcholinesterase from the guinea-pig isolated ileum. Br J Pharmacol 1989;97:490-498.

27. Kreis ME, Kasparek M, Zittel TT, Becker HD, Jehle EC. Neostigmine increases postoperative colonic motility in patients undergoing colorectal surgery. Surgery 2001;130:449-456.

28. Rubiales AS, Hernansanz S, Gutiérrez C, Del Valle ML, Flores LA. Neostigmine for refractory constipation in advanced cancer patients. J
Pain Symptom Manage 2006;32:204-205.

29. Saunders MD, Kimmey MB. Systematic review: acute colonic pseudo-obstruction. Aliment Pharmacol Ther 2005;22:917-925.

30. Imbimbo BP. Pharmacodynamic-tolerability relationships of cholinesterase inhibitors for Alzheimer's disease. CNS Drugs 2001;15: 375-390.

31. Jarvie EM, Cellek S, Sanger GJ. Potentiation by cholinesterase inhibitors of cholinergic activity in rat isolated stomach and colon. Pharmacol Res 2008;58:297-301.

32. Ward SM, Beckett EA, Wang X, Baker F, Khoyi M, Sanders KM. Interstitial cells of Cajal mediate cholinergic neurotransmission from enteric motor neurons. J Neurosci 2000;20:1393-1403.

33. Benham CD, Bolton TB, Lang RJ. Acetylcholine activates an inward current in single mammalian smooth muscle cells. Nature 1985;316: 345-347.

34. Inoue R, Isenberg G. Acetylcholine activates nonselective cation channels in guinea pig ileum through a G protein. Am J Physiol 1990; 258(6 Pt 1):C1173-C1178.

35. Sims SM. Cholinergic activation of a non-selective cation current in canine gastric smooth muscle is associated with contraction. J Physiol 1992;449:377-398.

36. Vogalis F, Sanders KM. Cholinergic stimulation activates a non-selective cation current in canine pyloric circular muscle cells. J Physiol 1990;429:223-236.

37. Bhetwal BP, Sanders KM, An C, Trappanese DM, Moreland RS, Perrino BA. $\mathrm{Ca}^{2+}$ sensitization pathways accessed by cholinergic neurotransmission in the murine gastric fundus. J Physiol 2013; 591(Pt 12):2971-2986.

38. Lammers WJ, Ver Donck L, Stephen B, Smets D, Schuurkes JA. Focal activities and re-entrant propagations as mechanisms of gastric tachyarrhythmias. Gastroenterology 2008;135:1601-1611.

39. Lammers WJ, Ver Donck L, Stephen B, Smets D, Schuurkes JA. Origin and propagation of the slow wave in the canine stomach: the outlines of a gastric conduction system. Am J Physiol Gastrointest Liver Physiol 2009;296:G1200-G1210.

40. O'Grady G, Du P, Lammers WJ, et al. High-resolution entrainment mapping of gastric pacing: a new analytical tool. Am J Physiol Gastrointest Liver Physiol 2010;298:G314-G321.

41. Bayguinov O, Hennig GW, Sanders KM. Movement based artifacts may contaminate extracellular electrical recordings from GI muscles. Neurogastroenterol Motil 2011;23:1029-1042, e498.

42. Bayguinov O, Ward SM, Kenyon JL, Sanders KM. Voltage-gated $\mathrm{Ca}^{2+}$ currents are necessary for slow-wave propagation in the canine gastric antrum. Am J Physiol Cell Physiol 2007;293:C1645-C1659.

43. Zheng H, Park KS, Koh SD, Sanders KM. Expression and function of a T-type $\mathrm{Ca}^{2+}$ conductance in interstitial cells of Cajal of the murine small intestine. Am J Physiol Cell Physiol 2014;306:C705C713. 